This item was submitted to Loughborough's Research Repository by the author.

Items in Figshare are protected by copyright, with all rights reserved, unless otherwise indicated.

\title{
On the effect of transient in-plane dynamics of the compression ring upon its tribological performance
}

PLEASE CITE THE PUBLISHED VERSION

http://dx.doi.org/10.1115/1.4028496

PUBLISHER

(C) ASME

VERSION

AM (Accepted Manuscript)

\section{PUBLISHER STATEMENT}

This work is made available according to the conditions of the Creative Commons Attribution-NonCommercialNoDerivatives 4.0 International (CC BY-NC-ND 4.0) licence. Full details of this licence are available at: https://creativecommons.org/licenses/by-nc-nd/4.0/

\section{LICENCE}

CC BY-NC-ND 4.0

\section{REPOSITORY RECORD}

Baker, Christopher E., Ramin Rahmani, Stephanos Theodossiades, Homer Rahnejat, and Brian Fitzsimons. 2019. "On the Effect of Transient In-plane Dynamics of the Compression Ring Upon Its Tribological Performance". figshare. https://hdl.handle.net/2134/16636. 
Journal of Engineering for Gas Turbines and Power, Transactions of the ASME, March 2015, Vol. 137, No. 3, Paper No: GTP-14-1296; DOI: 10.1115/1.4028496

(Accepted Version)

\title{
On the Effect of Transient In-plane Dynamics of the Compression
}

\section{Ring upon its Tribological Performance}

\author{
C. Baker ${ }^{*}$, R. Rahmani ${ }^{*}$, S. Theodossiades ${ }^{* 1}$, H. Rahnejat ${ }^{*}$ and B. Fitzsimons ${ }^{* *}$ \\ *Wolfson School of Mechanical \& Manufacturing Engineering, Loughborough University, \\ Loughborough, UK \\ ${ }^{* *}$ Aston Martin Lagonda, Gaydon, Warwickshire, UK \\ ${ }^{1}$ Corresponding Author: S.Theodossiades@lboro.ac.uk
}

\begin{abstract}
Energy losses in an internal combustion engine are either thermal or parasitic. The latter are the mechanical inefficiencies, chiefly as the result of generated friction. Nearly half of these losses are attributed to the piston-cylinder system. During idle and at low engine speeds, friction is the major contributor to the overall engine losses. In particular, the rather small top compression ring accounts for a disproportionate share. Therefore, detailed understanding of compression ring tribology/dynamics (referred to as tribo-dynamics) is essential. Moreover, the ring's primary sealing function may be breached by its elastodynamic behaviour. The reported analyses in literature do not account for the transient nature of ring elastodynamics, as an essential feature of ring-bore tribology. The transient in-plane dynamics of incomplete rings are introduced in the analysis and verified using an FEA model, in order to address this shortcoming. The methodology is then coupled with the tribological analysis of the top compression ring. Comparison is made with
\end{abstract}


Journal of Engineering for Gas Turbines and Power, Transactions of the ASME, March 2015, Vol. 137, No. 3, Paper No: GTP-14-1296; DOI: 10.1115/1.4028496

(Accepted Version)

experimental measurements which show the validity of the proposed method. The radial in-

plane elastodynamic response of the ring improves the accuracy of the frictional power loss calculations.

\section{Keywords}

IC engine, Piston compression ring, In-plane ring elastodynamics, friction, NEDC 
Journal of Engineering for Gas Turbines and Power, Transactions of the ASME, March 2015, Vol. 137, No. 3, Paper No: GTP-14-1296; DOI: 10.1115/1.4028496

\section{Nomenclature}

$A$ - Cross-sectional area of the ring

$A_{a}-$ Asperity contact area

$A_{c}-$ Nominal contact area of the ring's

face-width

$A_{n 1}-A_{n 6}-$ Modal function constants

$b$ - Ring face-width

$C_{n 1}, C_{n 2}-$ Time response constants

$d$ - Ring thickness

$d_{n}-$ Modal function constant

$e_{n}-$ Modal function constant

E- Young's modulus of elasticity

$E^{\prime}$ - Composite modulus of elasticity

$F_{e}-$ Ring tension

$F_{g}-$ Applied Gas force

$F_{\text {groove }}-$ Groove friction

$F_{R}-$ Net (residual) radial force

$F_{T}-$ Tangential shear force

$F_{5 / 2}-$ Greenwood \& Tripp statistical

function

$f_{n}-$ Modal function constant

$g-$ Ring gap

$h$ - Film thickness
(Accepted Version)

$h_{0}-$ Minimum film thickness

I-Second area moment of inertia of the ring cross-section

$i, j-$ Mode number (orthogonality

condition)

l- Connecting rod length

$m-$ Ring mass per unit length

$p$-Pressure

$p_{e}$ - Elastic pressure due to ring tension

$p_{g}$ - Gas pressure

$p_{l}-$ Top ring's leading edge pressure

$p_{t}-$ Top ring's trailing edge pressure

$Q_{n}-$ General forcing function

$r$-Crank-pin radius

$R-$ Ring nominal radius

$s-$ Ring axial profile

$t$-Time

$U$-Speed of entraining motion

$V$ - Tangential modal response

$v$ - Tangential displacement

W-Radial modal response

$W_{a}-$ Asperity load

$W_{h}-$ Lubricant reaction 
Journal of Engineering for Gas Turbines and Power, Transactions of the ASME, March 2015, Vol. 137, No. 3, Paper No: GTP-14-1296; DOI: 10.1115/1.4028496

$w$ - Radial displacement

$x-$ Direction of entraining motion

$y$ - Circumferential degree of freedom

\section{Greek symbols}

$\alpha$ - Incomplete ring subtended angle

B-Thermal coefficient of expansion

$\Delta$ - Global deformation of ring

$\delta$ - Local contact deformation

$\delta_{n}-$ Modal function constant

$\zeta$ - Asperity distribution per unit area

$\eta$ - Lubricant dynamic viscosity

$\eta_{0}-$ Ambient dynamic viscosity

$\theta$ - Temperature

$\theta_{0}-$ Ambient temperature

$\kappa$ - Average asperity tip radius

$\lambda_{n}-$ Frequency parameter

$\lambda_{s}-$ Stribeck oil film parameter

$\mu_{n}-$ Modal function constant
(Accepted Version)

$\xi_{n}$ - Time response of ring deflection

$\rho$ - Lubricant density

$\sigma-$ Roots of the eigenvalue problem

$\sigma_{1}, \sigma_{2}-$ Surface roughness values

$\sigma_{c}-$ Composite roughness of the

counterfaces

$\varsigma$-Coefficient of boundary shear strength

$\tau-$ Viscous shear stress

$\tau_{0}-$ Eyring shear stress of the lubricant

$\tau^{\prime}-$ Time segment

$\phi$-Crank angle

$\varphi$ - Direction along the ring periphery

$\omega_{f}-$ Excitation frequency

$\omega_{n}-$ Natural frequency

\section{Subscripts/Abbreviations}

$c$-Composite

$n$-Mode shape index

NEDC - New European Drive Cycle

\section{Introduction}

Owing to the finite nature of fossil fuel resources and the increasing concern with regard to the impact of industrialisation upon global warming, reduction in emissions and improved 
Journal of Engineering for Gas Turbines and Power, Transactions of the ASME, March 2015, Vol. 137, No. 3, Paper No: GTP-14-1296; DOI: 10.1115/1.4028496

(Accepted Version)

fuel efficiency have become the paramount concerns. This is no less evident than in the automobile industry, with independent studies setting strict emissions' targets [1]. These targets incur severe financial penalties for non-compliance, which are intended to ensure improved fuel efficiency. Some recent approaches include the use of hybrid technologies and electric drives. However, the internal combustion engine is expected to remain the main source of vehicle propulsion for the immediate future, at the very least. Therefore, improvements to its efficiency are a major industrial objective.

The in-cylinder parasitic losses are among the most significant sources of inefficiency in IC engines, particularly those attributed to the top compression ring-bore conjunction. This contact zone is also one of the most complex to analyse because of the ring's dynamic behaviour. Initial studies on ring dynamics were primarily concerned with prediction of its natural frequencies and mode shapes based on small curved bars [2]. This approach was extended by Den Hartog [3], who applied the Rayleigh-Ritz energy method to calculate the natural frequencies of hinged and clamped circular arches. Volterra and Morell [4] used the same approach to find the lowest natural frequencies, both in and out-of-plane of hinged and free elastic curved beams. Love [5] detailed the complete set of equations of motion for numerous structures, including curved beams. The dynamic response, as well as the modal characteristics of those structures, was then predicted. Timoshenko [6] stated that for thin rings, where the ring thickness is small compared with its radius, shearing deformation may be neglected.

Archer [7] studied the in-plane vibrations of an incomplete ring (a realistic representation of a compression ring), assuming an in-extensional neutral axis, solving the eigen-value problem and producing mode shapes. These solutions are comparable with those presented 
Journal of Engineering for Gas Turbines and Power, Transactions of the ASME, March 2015, Vol. 137, No. 3, Paper No: GTP-14-1296; DOI: 10.1115/1.4028496

\section{(Accepted Version)}

by Den Hartog [3]. The work by Archer [7] was based upon that of Ojalvo [8], who applied a similar method to present a solution for the out-of-plane ring dynamics. He used the main assumption that the in-plane and out-of-plane ring dynamics may be regarded as uncoupled. Lang [9] presented a comprehensive analysis of the in-plane dynamic response of extensional and in-extensional rings, obtaining a complete dynamic solution. A modal response example was presented and compared with experimental data, showing good agreement. Auciello and De Rosa [10] calculated the natural frequencies of rings with varying cross-sections after applying the thin, in-extensional assumptions for the ring, as well as neglecting its rotary inertia. A different approach was considered by Kang et al [11], who employed the Differential Quadrature Method (DQM) to obtain the in-plane and outof-plane eigenvalues.

Attempts to include the effects of ring deflection in the compression ring tribological analysis have been made. Namazian and Heywood [12] created a ring dynamics model, which also included a gas flow model. However, ring twist was not considered in their study. Dowson et al [13] and Ruddy et al [14] examined the influence of ring twist, suggesting that a particular contact profile (the ring's angle of twist with respect to the groove) between the ring and groove could cause flutter to occur. Their study did not include gas flow. It was assumed that the axial ring motion followed that of the piston once contact between the two bodies occurred. Tian [15] discussed how ring flutter and twist affected gas and oil flow in both gasoline and diesel engines. He stated that the critical pressure difference between the top and bottom of the ring (causing it to collapse) is given as:

$$
\mathrm{P}_{12, \text { critical }}=\frac{\mathrm{F}_{\mathrm{t}}}{\mathrm{B}_{1} \mathrm{R}}
$$


Journal of Engineering for Gas Turbines and Power, Transactions of the ASME, March 2015, Vol. 137, No. 3, Paper No: GTP-14-1296; DOI: 10.1115/1.4028496

(Accepted Version)

Where $\mathrm{Ft}$ is the ring tangential force and $\mathrm{R}$ is the cylinder bore radius. $\mathrm{B} 1$ denotes the axial distance between the minimum film position and the upper edge of the ring face. The inplane deformation of the piston ring was accounted for by D'Agostino et al [16], who used an FEA model. Hitherto, the open literature on tribology of the piston ring-cylinder liner conjunction does not include transient ring dynamics. The thin nature of the compression ring means that global deflections are highly likely during the engine cycle. Whilst ring flutter is a widely accepted problem with piston rings, an attempt to numerically investigate this phenomenon in conjunction with ring-bore friction has not been widely discussed in literature. Therefore, the inclusion of transient in-plane ring dynamics into a tribological study of the system constitutes one of the main contributions of the current study.

Large variations in the applied load, sliding speed, generated temperature and lubricant availability are factors that account for the complexity of ring-bore conjunction [17]. According to Taylor [18], at least 17 important influential parameters must be addressed, when simulating the ring-liner contact with the aim of achieving realistic predictions. Additionally, in an engine cycle, the piston ring-cylinder liner contact may experience all possible regimes of lubrication. The top compression ring, in particular, is subjected to the most severe environment in terms of temperature and load and, therefore, a considerable amount of effort has been expended to study this [19]. As Fox et al [20] have noted the quantity of lubricant in the piston ring zone has decreased sharply over the years to counter adverse environmental emissions. This reduction in lubricant mass flow rate has in turn added to the complexity of the problem. For instance, in the early 80 s, the top ring typically contributed around $13 \%$ to the total friction, attributed to a three ring- pack system. Almost two decades later the top ring's contribution to friction has increased by $27 \%$ in the same 
Journal of Engineering for Gas Turbines and Power, Transactions of the ASME, March 2015, Vol. 137, No. 3, Paper No: GTP-14-1296; DOI: 10.1115/1.4028496

\section{(Accepted Version)}

type of engine. Nowadays, in general, friction contribution from the top ring is considered to be between $13 \%$ to $40 \%$ of all the parasitic losses depending on the engine and the running conditions [21]. Therefore, the tribology of top compression ring-cylinder liner conjunction has been of great importance for many years. According to Priest and Taylor [22], a 10\% reduction in mechanical losses would lead to a $1.5 \%$ reduction in fuel consumption.

There has been a considerable effort to address the main factors influencing the tribology of the piston top compression ring-cylinder liner contact through both analytical/numerical, as well as experimental effort. The pioneering works by Furuhama [23-25] paved the way for both experimental and numerical investigations on compression ring-liner tribology. Since then, numerical analysis for piston-cylinder system has received considerable attention with the inclusion of many salient practical features. These comprise the inclusion of ring-bore comformability analysis by Ma et al [26] and Mishra et al [27], surface topography of contacting surfaces by Hu et al [28], as well as by Bolander et al [29]. Akalin and Newaz [30] and Mishra et al [31] used their transient mixed lubrication models and compared their results with those of an experimental motorised engine test rig by Furuhama and Sasaki [32], showing good agreement. The discrepancy between the aforementioned analyses and the experimentally measured friction were attributed to various parameters, chiefly the inherent bore out-of-roundness and ring dynamics, caused by pressure-induced loading. The former has been studied by Rahmani et al [33], whilst the effect of the latter on frictional losses under transient condition has not been reported.

Recently, Baker et al [34,35] addressed the issue of ring in-plane elastodynamic behaviour under forced excitation which can typically appear in an IC engine top compression ring's zone. The present study builds further on this issue by fully coupling the ring dynamics to 
Journal of Engineering for Gas Turbines and Power, Transactions of the ASME, March 2015, Vol. 137, No. 3, Paper No: GTP-14-1296; DOI: 10.1115/1.4028496

\section{(Accepted Version)}

the tribological analysis in a transient manner. The current study combines transient thermomixed regime of lubrication with elastodynamic response of the ring, thus providing a more practically realistic analysis. The results are compared with the experimental work of Takiguchi et al [36], showing improved accuracy, when ring modal behaviour is included in the tribological study.

\section{Introduction}

\subsection{Tribology of top ring/liner conjunction}

The generated hydrodynamic pressures in the ring-liner conjunction are obtained using Reynolds equation:

$$
\frac{\partial}{\partial x}\left[\left(\frac{\rho h^{3}}{6 \eta}\right) \frac{\partial p}{\partial x}\right]+\frac{\partial}{\partial y}\left[\left(\frac{\rho h^{3}}{6 \eta}\right) \frac{\partial p}{\partial y}\right]=\Delta U \frac{\partial}{\partial x}(\rho h)+2 \frac{\partial}{\partial t}(\rho h)
$$

where, $\Delta U=U_{1}-U_{2}=U_{2}$ (piston speed) since $U_{1}=0$ (stationary bore surface). Piston speed is a function of inertial dynamics [37]:

$$
U_{1}(\phi)=-r \dot{\phi} \sin \phi\left\{1+\cos \phi\left[\left(\frac{l}{r}\right)^{2}-\sin ^{2} \phi\right]^{-\frac{1}{2}}\right\}
$$

where, $\dot{\phi}=\partial \phi / \partial t$ is the nominal angular velocity of the crank.

The boundary conditions used in the solution of Reynolds equation are shown in equation (4); at the upper and lower boundaries of the ring the cylinder and crankcase pressure values are assumed, respectively [38]. Lubricant side leakage is neglected (a reasonable assumption, given the small quantity of the lubricant within the contact zone) and the pressure at the ring gap is taken as an average of the crankcase and cylinder pressures: 
Journal of Engineering for Gas Turbines and Power, Transactions of the ASME, March 2015, Vol. 137, No. 3, Paper No: GTP-14-1296; DOI: 10.1115/1.4028496

$$
\left\{\begin{array}{c}
p(0, y)=p_{l} \\
p(b, y)=p_{t} \\
p\left(x_{c}, y\right)=p_{c} \\
\left.\frac{d p(x, y)}{d x}\right|_{x=x_{c}}=0 \\
p(x, 0)=p(x, 2 \pi)=\frac{p_{l}+p_{t}}{2}
\end{array}\right.
$$

where, the leading (inlet) and trailing (outlet) pressures are $p_{l}$ and $p_{t}$, respectively. These can take in-cylinder or crankcase pressure values, depending on the direction of piston motion. Fully flooded conditions have been assumed for this study, this being an approach used in many previous analyses

Variation of lubricant density with generated pressures and contact temperature is given as [39]:

$$
\rho=\rho_{0}\left[1+\frac{0.6 \times 10^{-9}\left(p-p_{0}\right)}{1+1.7 \times 10^{-9}\left(p-p_{0}\right)}\right]\left[1-\beta\left(\theta-\theta_{0}\right)\right]
$$

And for lubricant dynamic viscosity [40]:

$$
\eta=\eta_{0} e^{\alpha^{*} p}
$$

Where $\alpha^{*}$ is a function depending on pressure $p$ (in $\mathrm{Pa}$ ) and temperature $\theta$ (in $\mathrm{K}$ ), as well as some the predetermined constants:

$$
\alpha^{*}=\frac{1}{p}\left[\ln \eta_{0}+9.67\right]\left\{\left(\frac{\theta-138}{\theta_{0}-138}\right)^{-S_{0}}\left(1+\frac{p}{1.98 \times 10^{8}}\right)^{Z}-1\right\}
$$

Where coefficients $S_{0}$ and $Z$ are defined by Gohar and Rahnejat [41]. The lubricant bulk rheological properties at atmospheric pressure are given in Table 1 . The lubricant used in the presented analysis is SAE $10 \mathrm{~W} 40$. 
Journal of Engineering for Gas Turbines and Power, Transactions of the ASME, March 2015, Vol. 137, No. 3, Paper No: GTP-14-1296; DOI: 10.1115/1.4028496

Table 1: Lubricant properties

\begin{tabular}{|l|l|l|}
\hline Parameter & Value & Unit \\
\hline Pressure-viscosity coefficient & $2 \times 10^{-8}$ & $\mathrm{~m}^{2} / \mathrm{N}$ \\
\hline Thermal expansion coefficient & $6.5 \times 10^{-4}$ & $1 / \mathrm{K}$ \\
\hline Lubricant density & 849.7 at $15^{\circ} \mathrm{C}$, & $\mathrm{kg} / \mathrm{m}^{3}$ \\
& 833.8 at $40^{\circ} \mathrm{C}$ & \\
\hline Lubricant kinematic viscosity & 59.99 at $40^{\circ} \mathrm{C}$, & $\times 10^{-6} \mathrm{~m}^{2} / \mathrm{s}$ \\
& 9.59 at $100^{\circ} \mathrm{C}$ & \\
\hline
\end{tabular}

The ring-liner gap can be presented as:

$$
h(x, y, t)=h_{m}(t)+h_{s}(x)+\Delta_{s}(y, t)+\Delta_{t h}(y, t)+\Delta_{d}(y, t)+\delta(p)
$$

where, the overall gap, $h$ (film thickness) comprises several constituents; $\delta$ is the localised contact deformation. $\Delta_{\mathrm{s}}, \Delta_{\mathrm{th}}$, and $\Delta_{\mathrm{d}}$ represent the 'global' elastostatic, thermoelastic and elastodynamic deformation of either the ring and/or the liner. The initial distortion which exists in a fitted liner within the engine block or due to the tightening of the cylinder head bolts, if not accommodated by the fitted ring in the liner will yield a non-zero value for $\Delta_{\mathrm{S}}$. A thermoelastic analysis may provide the thermally deformed bore profile for which the emerging gap can be included in $\Delta_{\text {th }} . \Delta_{\mathrm{d}}$ takes into account the change in the ring/liner gap due to deformations caused by mechanical vibrations of the bore and/or the ring under transient loads. The inclusion of thermal distortions is not within the scope of the current analysis. In addition, the effects of bore out-of-roundness on static deformations and ring/liner conformability have already been comprehensively studied elsewhere [33], and so are not included in the current analysis, along with localised deformations. $h_{m}$ represents 
Journal of Engineering for Gas Turbines and Power, Transactions of the ASME, March 2015, Vol. 137, No. 3, Paper No: GTP-14-1296; DOI: 10.1115/1.4028496

\section{(Accepted Version)}

the variations in the minimum film thickness with time and $h_{s}[\mu \mathrm{m}]$ is the ring face-width profile, which is usually considered to be parabolic ( $x$ is the distance along the ring facewidth in $\mathrm{mm}$ ). However, the actual worn run-in ring profile which is closer to a hexanomial fit is used in the current analysis [33]:

$h_{s}(x)=-6.493 x^{6}-49.845 x^{5}+143.22 x^{4}-98.541 x^{3}+27.351 x^{2}-17.338 x+7.4986$

The comparison between a new and a worn ring axial profile is shown in figure 1 . The ring profile effect on the lubricant input boundary conditions can be clearly seen, considering the $x$ axis in figure 1 to be the liner wall.

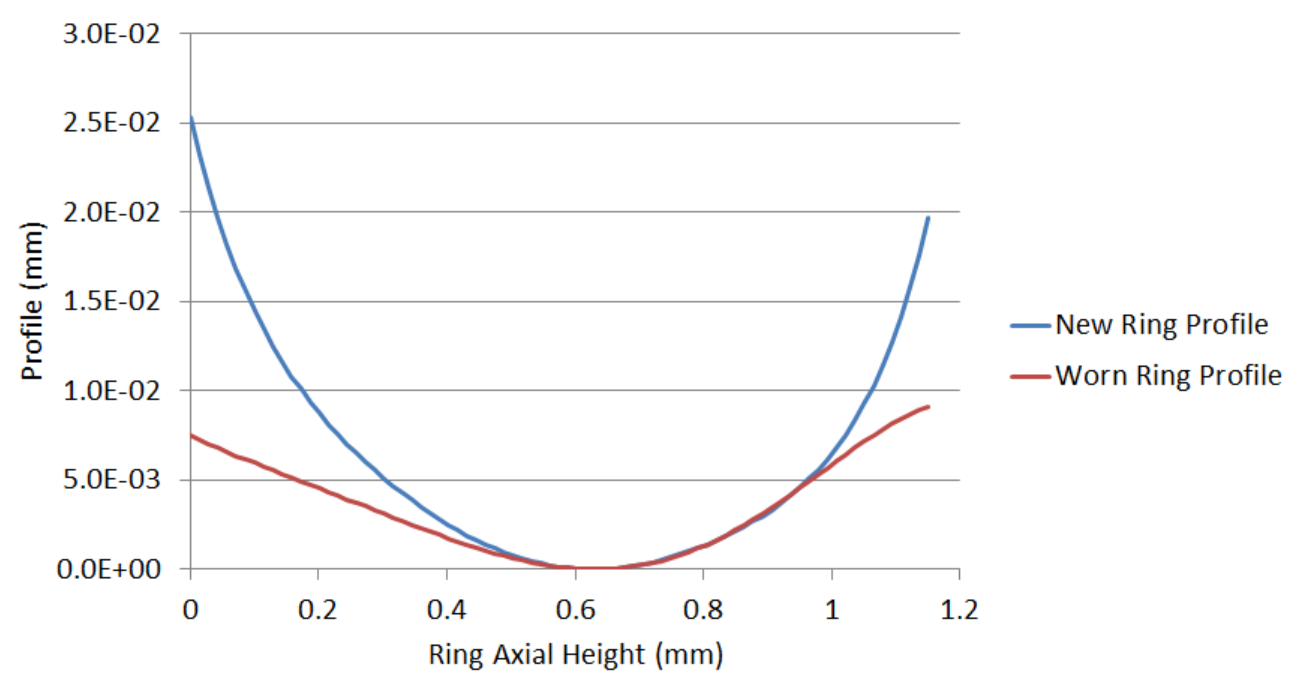

Figure 1: Comparison between new and worn ring profiles

The ring face-width used in this study is similar to that used in Rahmani et al [33]. The profile of a new ring is assumed for most of the presented results. However, a worn ring profile is considered as well. The latter is measured after a 150h high speed engine test, which is representative of engine testing protocol for high performance engines.

In the mixed regime of lubrication when the film ratio $\lambda_{s}=\frac{h}{\sigma_{c}}<3\left(\sigma_{c}=\left(\left(\sigma_{1}^{2}+\sigma_{2}^{2}\right)^{1 / 2}\right)\right)$, 
Journal of Engineering for Gas Turbines and Power, Transactions of the ASME, March 2015, Vol. 137, No. 3, Paper No: GTP-14-1296; DOI: 10.1115/1.4028496

\section{(Accepted Version)}

the load carried by asperities needs to be taken into account. The procedure and appropriate relations are provided below. The parameters used for this purpose have been measured and are shown in Table 2.

Table 2: Ring and liner surface topographical parameters

\begin{tabular}{|l|l|l|}
\hline Parameter & Value & Unit \\
\hline Ra for liner, $\sigma_{1}$ & 0.260 & $\mathrm{~mm}$ \\
\hline Ra for new ring, $\sigma_{2}$ & 0.408 & $\mathrm{~mm}$ \\
\hline Ra for worn ring, $\sigma_{2}$ & 0.235 & $\mathrm{~mm}$ \\
\hline Roughness parameter, $\left(\mathrm{K} \sigma_{\mathrm{c}}\right.$ & 0.074 & - \\
\hline Measure of asperity gradient, $(\sigma / \mathrm{K})_{\mathrm{c}}$ & 0.309 & - \\
\hline
\end{tabular}

The ring tension force is obtained from the relationship for the ring elastic pressure in Bin Chik and Fessler [42] as:

$$
F_{e}=\iint P_{e} d x d y=\iint \frac{E I g}{3 \pi b R^{4}} d x d y
$$

The gas force is also calculated using the in-cylinder measured pressure variations in an engine test:

$$
F_{g}=\iint P_{g} d x d y
$$

Figure 2 shows the variations of in-cylinder pressure at various engine speeds. 
Journal of Engineering for Gas Turbines and Power, Transactions of the ASME, March 2015, Vol. 137, No. 3, Paper No: GTP-14-1296; DOI: 10.1115/1.4028496

(Accepted Version)

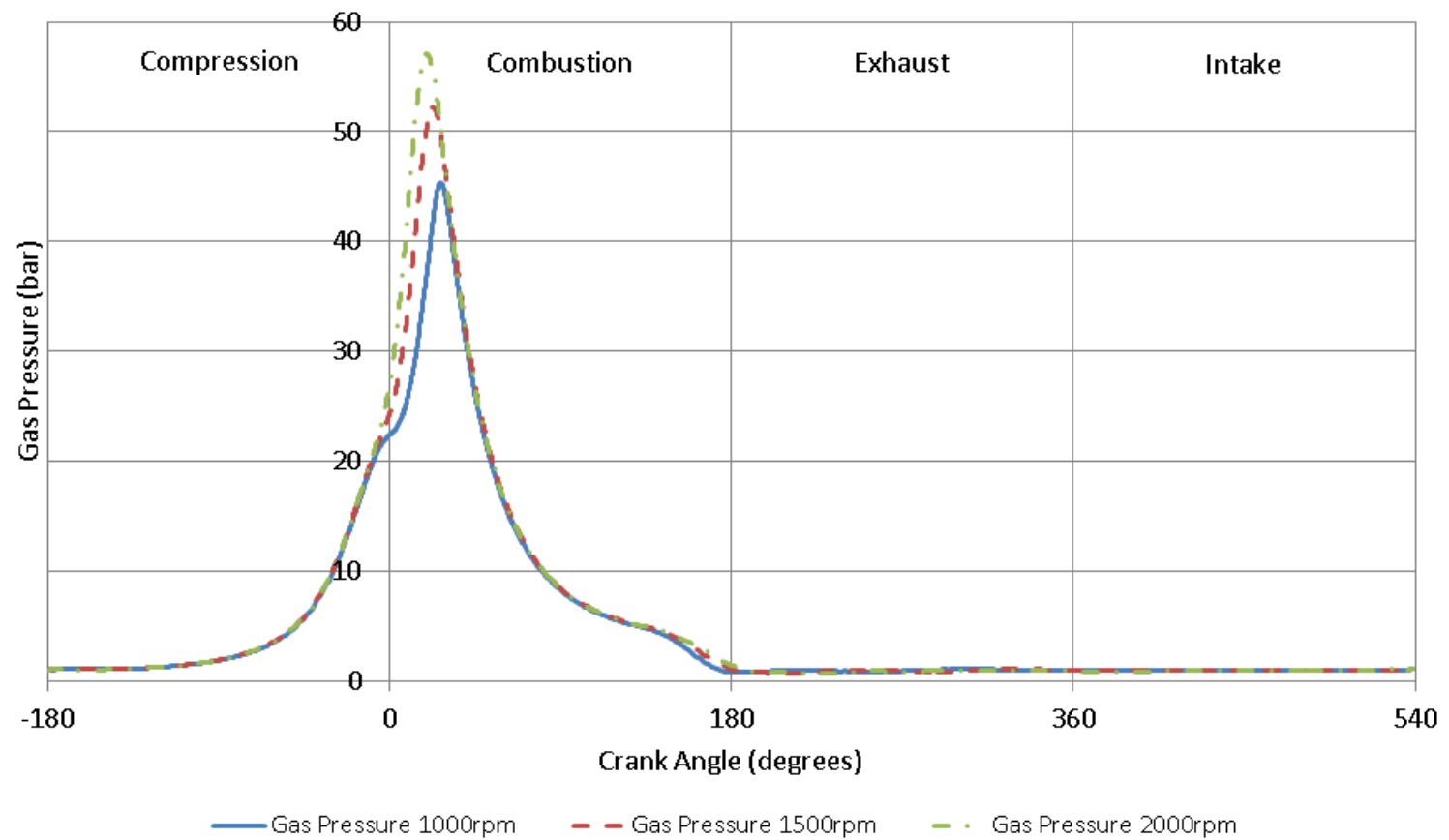

Figure 2: Pressure variation in the combustion chamber for different engine speeds

In a quasi-static analysis, at any crank angle (instant of time), the load applied on the ring by the gas force, $F_{g}$, in addition to any inherent ring tension force, $F_{e}$ should be equated with the hydrodynamic load capacity (obtained by integrating the local pressure distribution in the ring-liner conjunction), as well as the load carried by surface asperities (figure 3) (assuming the groove friction to be negligible):

$$
F_{e}+F_{g}=W_{h}+W_{a}
$$

and: $W_{h}=\iint p d x d y$ and $W_{a}=\frac{8 \sqrt{2}}{15} \pi\left(\zeta \kappa \sigma_{c}\right)^{2} \sqrt{\frac{\sigma_{c}}{\kappa}} E^{\prime} A_{c} F_{5 / 2}\left(\lambda_{s}\right)$

where, the product $\zeta \kappa \sigma$ is known as the roughness parameter [43] and the statistical function in (9) is given as [44]:

$$
F_{5 / 2}\left(\lambda_{s}\right)=\max \left\{-0.004 \lambda_{s}{ }^{5}+0.057 \lambda_{s}{ }^{4}-0.296 \lambda_{s}{ }^{3}+0.784 \lambda_{s}{ }^{2}-1.078 \lambda_{s}+0.617,0\right\}
$$


Journal of Engineering for Gas Turbines and Power, Transactions of the ASME, March 2015, Vol. 137, No. 3, Paper No: GTP-14-1296; DOI: 10.1115/1.4028496

\section{(Accepted Version)}

The nominal contact area, $A_{c}$, is given as:

$$
A_{c}=2 \pi R b
$$

The relationship in equation (11) (i.e. quasi-static equilibrium) only holds when the ring's elastodynamic modal behaviour is discounted. In this case, the algebraic sum of the above mentioned forces should equate the ring inertial force, if the ring rigid body motion is taken into account $[44,45]$. However, when ring elastodynamics is taken into account (which inherently incorporates the ring's lateral rigid body dynamics as well), the instantaneous equation of motion yields the residual excitation forces, $F_{R}$ as:

$$
F_{R}=\left(F_{e}+F_{g}\right)-\left(W_{h}+W_{a}\right)
$$

This residual force causes both rigid body inertial motion of the ring in the radial lateral direction as well as its modal in-plane deformation behaviour.

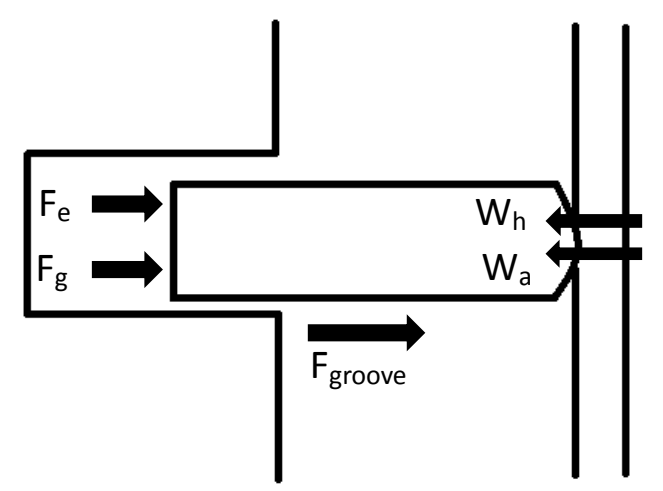

Figure 3: Free body diagram of the in-plane forces acting upon the piston ring within its groove 
Journal of Engineering for Gas Turbines and Power, Transactions of the ASME, March 2015, Vol. 137, No. 3, Paper No: GTP-14-1296; DOI: 10.1115/1.4028496

\subsection{Ring in-plane dynamics}

(Accepted Version)

The method described here is partially described in Baker et al [35]. In the present work, the in-plane dynamics methodology is combined with the lubricant reaction acting upon the ring, with the deformed ring profile. Figure 4 shows the degrees of freedom involved in the ring's in-plane dynamic analysis, as well as the forces and moments acting upon the ring. It is assumed that the ring can be treated as a thin structure, since it has a neutral radius-tothickness ratio of approximately 12.3 [9]. The neutral radius is also assumed to be inextensible, meaning that the degrees of freedom in Figure 4(a) are related as $w=\frac{\partial v}{\partial \varphi}$.

Rotary inertia is assumed to be negligible. The external excitation terms can be seen in Figure $4(b)$ for a cross-section of the examined ring. The forces acting on the compression ring-cylinder liner contact can be seen in Figure 3 (with the friction between the groove and the ring assumed to be negligible when compared with the other forces). The equations of motion describing the ring, as stated by Lang [9], are:

$$
\begin{aligned}
& \frac{\partial^{6} v}{\partial \varphi^{6}}+2 \frac{\partial^{4} v}{\partial \varphi^{4}}+\frac{\partial^{2} v}{\partial \varphi^{2}}+\frac{1}{p \omega_{0}^{2}} \frac{\partial^{4} v}{\partial \varphi^{2} \partial t^{2}}-\frac{1}{p \omega_{0}^{2}} \frac{\partial^{2} v}{\partial t^{2}}=\frac{a^{3}}{E I}\left\{\frac{\partial^{2}}{\partial \varphi^{2}}\left[F_{R}(\varphi, t)\right]-\left[F_{T}(\varphi, t)\right]\right\} \\
& \frac{\partial^{6} w}{\partial \varphi^{6}}+2 \frac{\partial^{4} w}{\partial \varphi^{4}}+\frac{\partial^{2} w}{\partial \varphi^{2}}+\frac{1}{p \omega_{0}^{2}} \frac{\partial^{4} w}{\partial \varphi^{2} \partial t^{2}}-\frac{1}{p \omega_{0}^{2}} \frac{\partial^{2} w}{\partial t^{2}}=\frac{a^{3}}{E I}\left\{\frac{\partial^{2}}{\partial \varphi^{2}}\left[F_{R}(\varphi, t)\right]-\frac{\partial}{\partial \varphi}\left[F_{T}(\varphi, t)\right]\right\}
\end{aligned}
$$


Journal of Engineering for Gas Turbines and Power, Transactions of the ASME, March 2015, Vol. 137, No. 3, Paper No: GTP-14-1296; DOI: 10.1115/1.4028496

(Accepted Version)
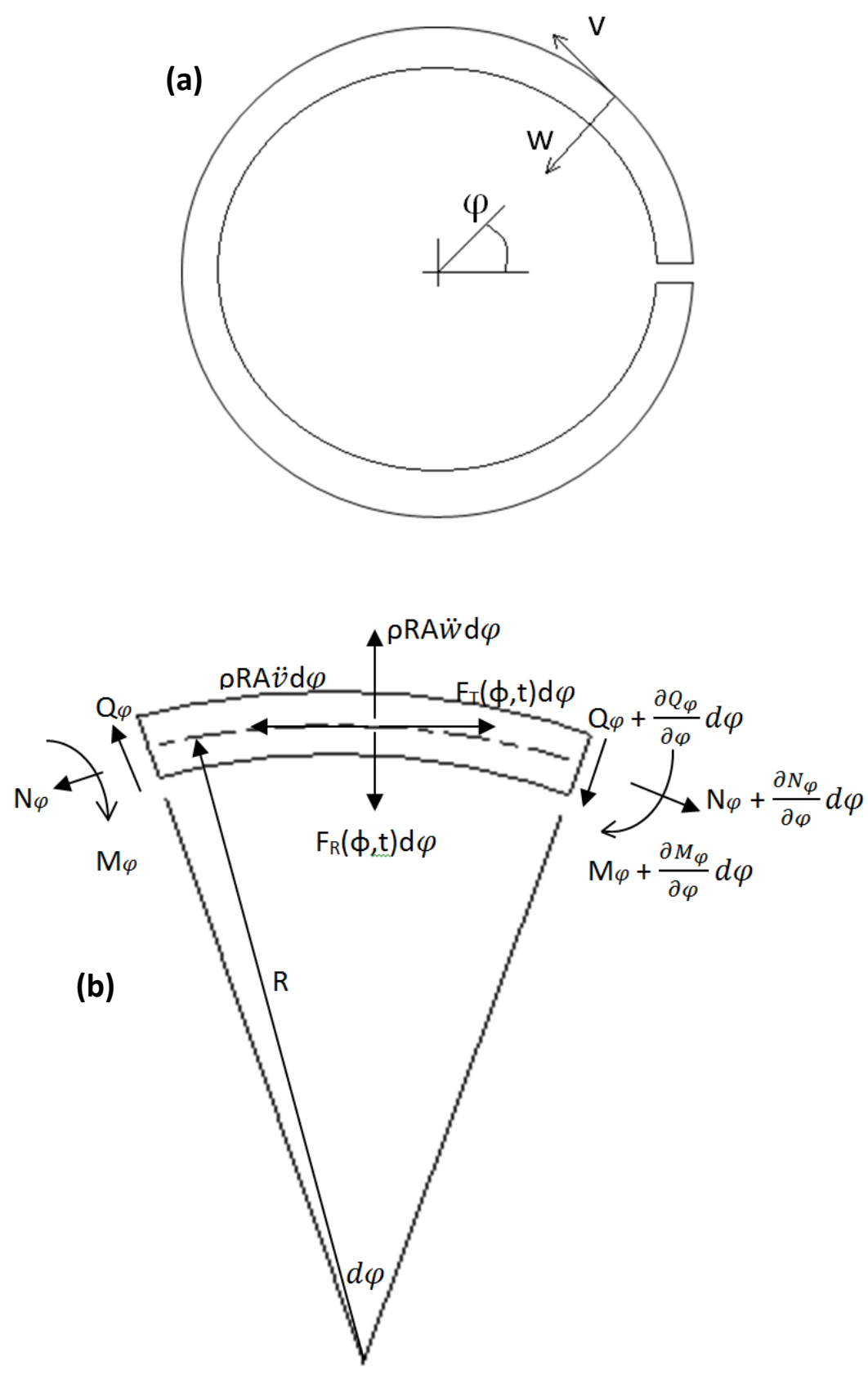

Figure 4: (a) Degrees of freedom when discussing the in-plane dynamics [30], and (b) forces and moments acting upon a ring segment [9]

The solution to equations $(16,17)$ comprises space-domain and time-varying terms $[9,30]$ :

$$
v(\varphi, t)=\sum_{n=1}^{\infty} V_{n}(\varphi) \xi_{n}(t)
$$

The space-domain term requires the calculation of the natural frequencies and mode shapes 
Journal of Engineering for Gas Turbines and Power, Transactions of the ASME, March 2015, Vol. 137, No. 3, Paper No: GTP-14-1296; DOI: 10.1115/1.4028496

(Accepted Version)

of equations $(16,17)$. For this purpose, the excitation terms are set to zero, which yields the following expression for the characteristic equation [30]:

$$
\sigma_{n}^{6}+2 \sigma_{n}^{4}+\left(1-\lambda_{n}\right) \sigma_{n}^{2}+\lambda_{n}=0
$$

Equation (19) is a cubic equation in $\sigma_{n}{ }^{2}$, the roots of which are represented by terms $d_{n}, e_{n}$ and $f_{n}$ in mode shape equations $(20,21)$ below. The roots of equation (19) are generic, represented as a function of the frequency parameter $\lambda_{n}$. The solution forms for $V_{n}$ and $W_{n}$ mode shape functions have been described by Lang [9] and Baker et al [35]. However, the mode shape functions consist of six trigonometric expressions of the following form:

$$
\begin{gathered}
V_{n}=A_{n 1} \cos d_{n} \varphi+A_{n 2} \sin d_{n} \varphi+A_{n 3} \cos e_{n} \varphi+A_{n 4} \sin e_{n} \varphi+A_{n 5} \cos f_{n} \varphi+ \\
A_{n 6} \sin f_{n} \varphi \\
W_{n}=-A_{n 1} d_{n} \sin d_{n} \varphi+A_{n 2} \mathrm{~d}_{\mathrm{n}} \cos \mathrm{d}_{\mathrm{n}} \varphi-A_{n 3} e_{n} \sin e_{n} \varphi+A_{n 4} e_{n} \cos e_{n} \varphi \\
-A_{n 5} f_{n} \sin f_{n} \varphi+A_{n 6} f_{n} \cos f_{n} \varphi
\end{gathered}
$$

The mode shapes depend on the boundary conditions employed. For the case of a compression ring, these are assumed to be free-free. Therefore, the bending moment, normal force and shear force are all zero at the two ends of the incomplete circular ring [35]:

$$
\begin{gathered}
\frac{d^{2} V_{n}}{d \varphi^{2}}+\frac{d^{4} V_{n}}{d \varphi^{4}}=0 \\
-\lambda \frac{d V_{n}}{d \varphi}+\frac{d^{3} V_{n}}{d \varphi^{3}}+\frac{d^{5} V_{n}}{d \varphi^{5}}=0 \\
\frac{d V_{n}}{d \varphi}+\frac{d^{3} V_{n}}{d \varphi^{3}}=0
\end{gathered}
$$

The solution of the characteristic equation gives the values of $\lambda_{n}$, which are used to calculate the natural frequency for each mode $n$ as [9]: 
Journal of Engineering for Gas Turbines and Power, Transactions of the ASME, March 2015, Vol. 137, No. 3, Paper No: GTP-14-1296; DOI: 10.1115/1.4028496

$$
\begin{aligned}
& \text { (Accepted Version) } \\
& \qquad \omega_{n}=\sqrt{\frac{\lambda_{n} E I}{m R^{4}}}
\end{aligned}
$$

The constants $A_{n 1-6}$ in equations $(20,21)$ must satisfy the orthogonality conditions. Equation (21) is substituted into the boundary condition equations. Rearranging these functions to find expressions for $A_{n 1-5}$ in terms of $A_{n 6}$ and solving the following orthogonality condition yields:

$$
\int_{0}^{\alpha} \rho R A\left(V^{2}+W^{2}\right) d \varphi=1
$$

Which leads to the values of $A_{n 1-6}$. The time term in equation (18) is calculated, neglecting damping as [9]:

$$
\ddot{\xi}_{n}+\omega_{n}^{2} \xi_{n}=Q_{n}(t)
$$

The right hand side of equation (27) takes the following form [9, 35]:

$$
Q_{n}(t)=-\frac{\int_{0}^{\alpha} V_{n}\left\{\frac{\partial}{\partial \varphi} F_{R}(\varphi, t)-F_{T}(\varphi, t)\right\} d \varphi}{\rho a A \int_{0}^{\alpha}\left(W_{n}^{2}+V_{n}^{2}\right) d \varphi}
$$

The forcing function of equation (15) is substituted into equation (28) as an excitation force in the radial direction. In this study it is assumed that there is no ring circumferential motion (i.e. constrained). Therefore: $F_{T}=0$. The solution to equation (25) is found by using the initial displacement and velocity conditions $\left(C_{n 2}\right.$ and $C_{n 1}$, respectively) [9]:

$$
\xi_{n}(t)=\frac{1}{\omega_{n}} \int_{0}^{t} Q_{n}\left(\tau^{\prime}\right) \sin \omega_{n}\left(t-\tau^{\prime}\right) d \tau^{\prime}+C_{n 1} \sin \omega_{n} t+C_{n 2} \cos \omega_{n} t
$$

Substitution of equation (29) into equation (18) alongside the mode shapes returns the inplane dynamics for an incomplete ring.

\subsection{Friction in mixed regime of lubrication}


Journal of Engineering for Gas Turbines and Power, Transactions of the ASME, March 2015, Vol. 137, No. 3, Paper No: GTP-14-1296; DOI: 10.1115/1.4028496

\section{(Accepted Version)}

Total friction would be a combination of the hydrodynamic shear of a lubricant film and boundary friction at the tip of the counterface opposing asperities. The latter takes into account dry contact of asperity peaks and the effect of any thin adsorbed film of boundary active lubricant species in non-Newtonian shear according to the Eyring model as $[46,47]$ :

$$
f_{b}=\tau_{0} A_{a}+\varsigma W_{a}
$$

Where, for the engine oil used: $\tau_{0}=2 \mathrm{MPa}$ and for a Ni-Cr-Mo sputter-coated ring's facewidth: $\varsigma=0.3038$ (for a new ring) and $\varsigma=0.2012$ for the worn run-in case.

The asperity contact area, $A_{a}$ is given as [42]:

$$
A_{a}=\pi^{2}\left(\zeta \beta \sigma_{c}\right)^{2} A F_{2}\left(\lambda_{s}\right)
$$

where, the statistical function is given as $[43,47]$ :

$$
F_{2}\left(\lambda_{s}\right)=-0.0018 \lambda_{s}^{5}+0.0281 \lambda_{s}^{4}-0.1728 \lambda_{s}^{3}+0.5258 \lambda_{s}^{2}-0.8043 \lambda_{s}+0.5003
$$

In regions, where a coherent film of lubricant is formed, the hydrodynamic shear stress comprises the pressure-induced component and that due to the relative sliding motion of surfaces, thus:

$$
\vec{\tau}=\left| \pm \frac{h}{2} \vec{\nabla} p-\Delta \vec{V} \frac{\eta}{h}\right|
$$

where, $\|\Delta \vec{V}\|=\Delta U=U_{1}$ and the gradient $\vec{\nabla} \equiv\left(\frac{\partial}{\partial x} \hat{\imath}+\frac{\partial}{\partial y} \hat{\jmath}\right)$ (the negative signs are used for the liner surface, while the positive sign stands for the ring surface). The hydrodynamic friction is obtained by integrating the hydrodynamic shear over the viscous contact area which is $A-A_{a}$, with $A_{a}<<$, thus:

$$
f_{v}=\int_{A-A_{a}} \vec{\tau}_{v} d A
$$


Journal of Engineering for Gas Turbines and Power, Transactions of the ASME, March 2015, Vol. 137, No. 3, Paper No: GTP-14-1296; DOI: 10.1115/1.4028496

(Accepted Version)

The total friction is obtained as: $f_{T}=f_{b}+f_{v}$, and the frictional power loss is obtained as:

$$
P=f_{T} U_{1}
$$

\subsection{Solution procedure}

The computation procedure is highlighted in the flowchart of figure 5.

Step 1: At each crank angle, commencing with the beginning of the compression stroke at $\phi=-180^{\circ}$, a simultaneous solution to Reynolds equation (2), film shape (8) and lubricant rheological state equations $(5,6)$ is obtained. A pressure convergence criterion is used in the iteration process. This represents the instantaneous tribological analysis. The method of solution is known as the Point Successive Over-Relaxation (PSOR) iterative method [48].

Step 2: The resulting pressure distribution is integrated to calculate the hydrodynamic load carrying capacity (equation (12)).

Step 3: With the film thickness also obtained, the Stribeck's oil film parameter is calculated. Using equations (12) and (13) the load carried by the asperities is also determined.

Step 4: Gas and elastic loads are determined from equations (9) and (10).

Step 5: For an assumed rigid ring, condition (11) (load balance) is satisfied within a specified percentage error. If this condition is not met, the minimum gap (clearance) is altered within the over-relaxation technique and steps 1-4 are repeated. 
Journal of Engineering for Gas Turbines and Power, Transactions of the ASME, March 2015, Vol. 137, No. 3, Paper No: GTP-14-1296; DOI: 10.1115/1.4028496

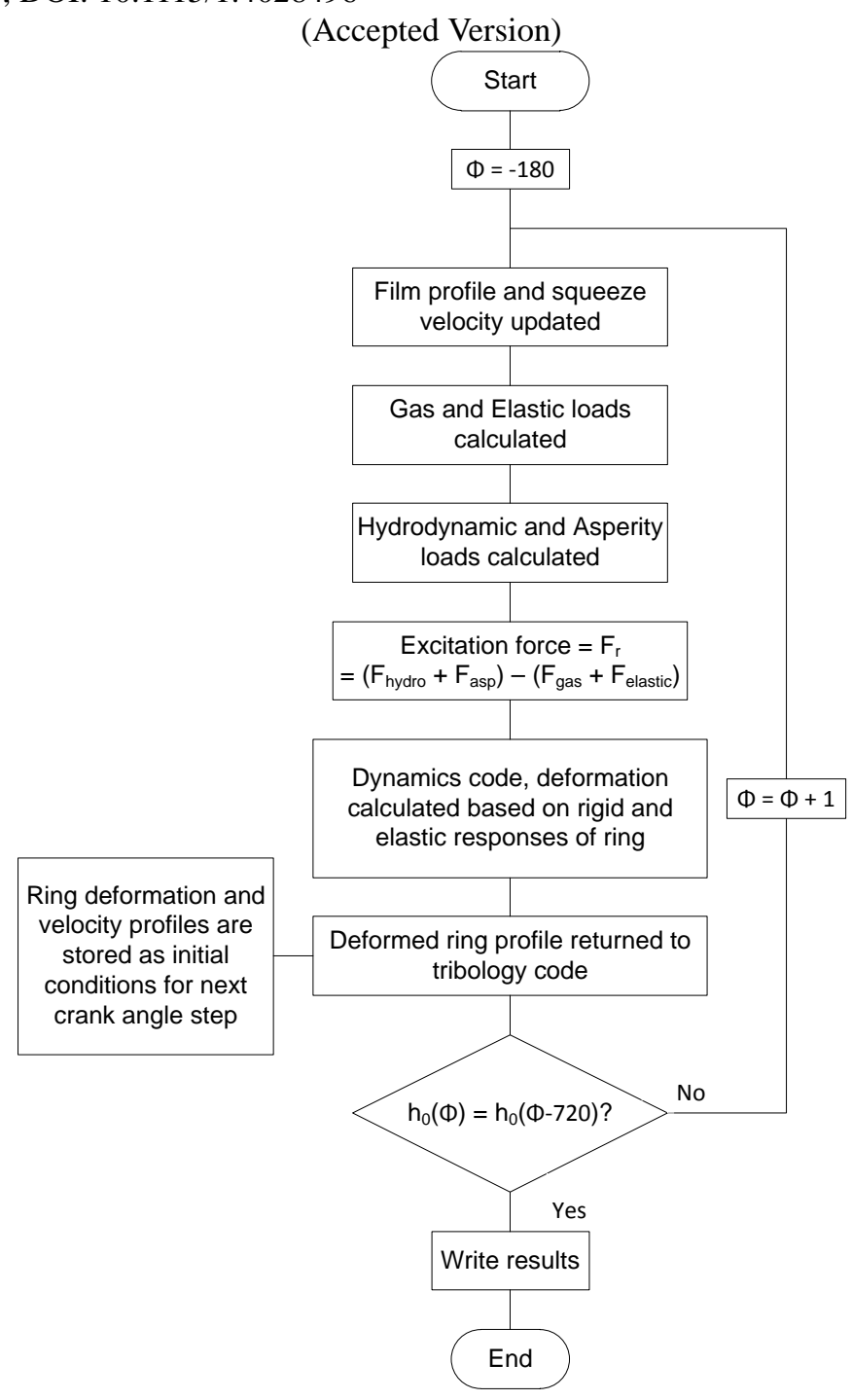

Figure 5: Algorithm of the coupling between the tribology and dynamics methodologies

Step 6: In the case of an elastic ring, the residual excitation force is calculated, using equation (17). The in-plane deformation of the ring is obtained through solution of equations (19), (26), (28) and (29); thus (18).

Step 7: The film shape equation (8) is adjusted to take into account the deformation of the elastic ring in all peripheral contact locations. Then, steps 1-4 are followed, but no quasistatic equilibrium is sought (i.e. the elastic ring is subject to transience).

Step 8: Boundary and viscous friction contributions, thus the total friction is obtained using 
Journal of Engineering for Gas Turbines and Power, Transactions of the ASME, March 2015, Vol. 137, No. 3, Paper No: GTP-14-1296; DOI: 10.1115/1.4028496

equations (30) and (34).

Step 9: The crank angle is advanced, typically by $1^{\circ}$ and the entire procedure is repeated for a complete 4-stroke engine cycle.

\section{Results and discussion}

The analyses reported here correspond to the compression ring-liner conjunction of a high performance V12, 4-stroke gasoline engine. Some of the ring properties are listed in Table 3.

Table 3: Properties of the examined compression ring

\begin{tabular}{|l|l|l|}
\hline Parameter & Value & Unit \\
\hline Elastic modulus, $\mathrm{E}$ & 203 & $\mathrm{GPa}$ \\
\hline Ring density, $\rho$ & 7800 & $\mathrm{~kg} / \mathrm{m}^{3}$ \\
\hline Ring thickness, $\mathrm{d}$ & 3.5 & $\mathrm{~mm}$ \\
\hline Axial face-width, $\mathrm{b}$ & 1.15 & $\mathrm{~mm}$ \\
\hline Nominal face-width radius, $\mathrm{R}$ & 44.52 & $\mathrm{~mm}$ \\
\hline Ring second moment of area, I & $2.25 \times 10^{-12}$ & $\mathrm{~m}$ \\
\hline End gap size (free ring), $\mathrm{g}$ & 10.5 & $\mathrm{~mm}$ \\
\hline Temperature, $\theta$ & 313 & $\mathrm{~K}$ \\
\hline
\end{tabular}

The analyses are carried out at low engine speeds of 1000-2000 rpm. Cylinder pressure values are shown in figure 2. TDC is marked by the crank angle of $0^{\circ}$ and the point of maximum pressure occurs at $20^{\circ}$ crank angle advance past the TDC in the power stroke. The engine speeds chosen for the various analyses correspond to the New European Drive Cycle 
Journal of Engineering for Gas Turbines and Power, Transactions of the ASME, March 2015, Vol. 137, No. 3, Paper No: GTP-14-1296; DOI: 10.1115/1.4028496

(Accepted Version)

(NEDC) [50]. These are for typical low speed city driving conditions or idling in traffic under "cold" or "hot" engine states. The analyses also include traditionally assumed fitted rigid ring within an idealised right circular cylindrical bore and a more representative elastic ring subjected to in-plane modal behaviour.

Figures 6-8 show a comparison between the numerical predictions made with an assumed rigid ring and those including the ring's in-plane modal response. These present the variations in the minimum film thickness, total frictional power loss, and lubricant flow rate throughout the engine's 4-stroke cycle at the speed of $1500 \mathrm{rpm}$, which represents idling to crawling vehicle speed in congested traffic. The combustion curve for this condition is shown in figure 2. The point of maximum pressure takes place $20^{\circ}$ past the TDC. 
Journal of Engineering for Gas Turbines and Power, Transactions of the ASME, March 2015, Vol. 137, No. 3, Paper No: GTP-14-1296; DOI: 10.1115/1.4028496

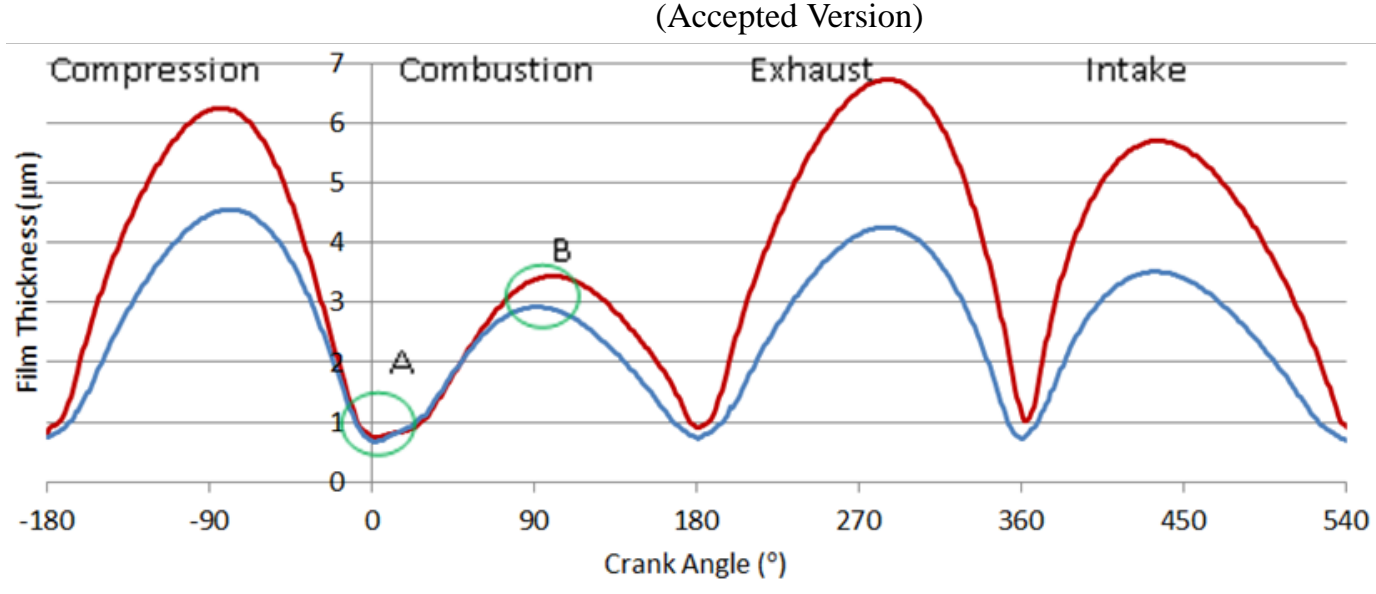

—1500rpm Rigid Ring _ -1500rpm Elastic Ring

Figure 6: Minimum film thickness comparison of rigid and elastic ring analysis for lubricant

temperature $40^{\circ} \mathrm{C}$

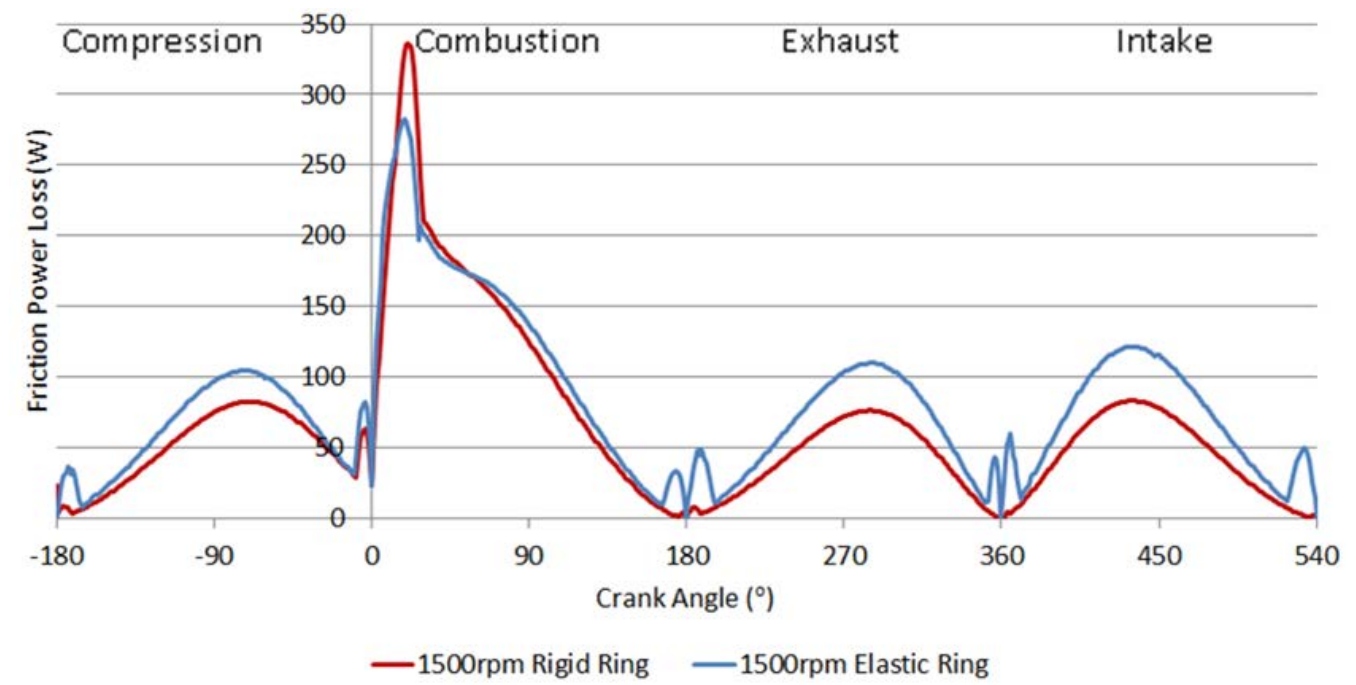

Figure 7: Frictional power loss comparison of rigid and elastic ring analysis for lubricant temperature $40^{\circ} \mathrm{C}$ 
Journal of Engineering for Gas Turbines and Power, Transactions of the ASME, March 2015, Vol. 137, No. 3, Paper No: GTP-14-1296; DOI: 10.1115/1.4028496

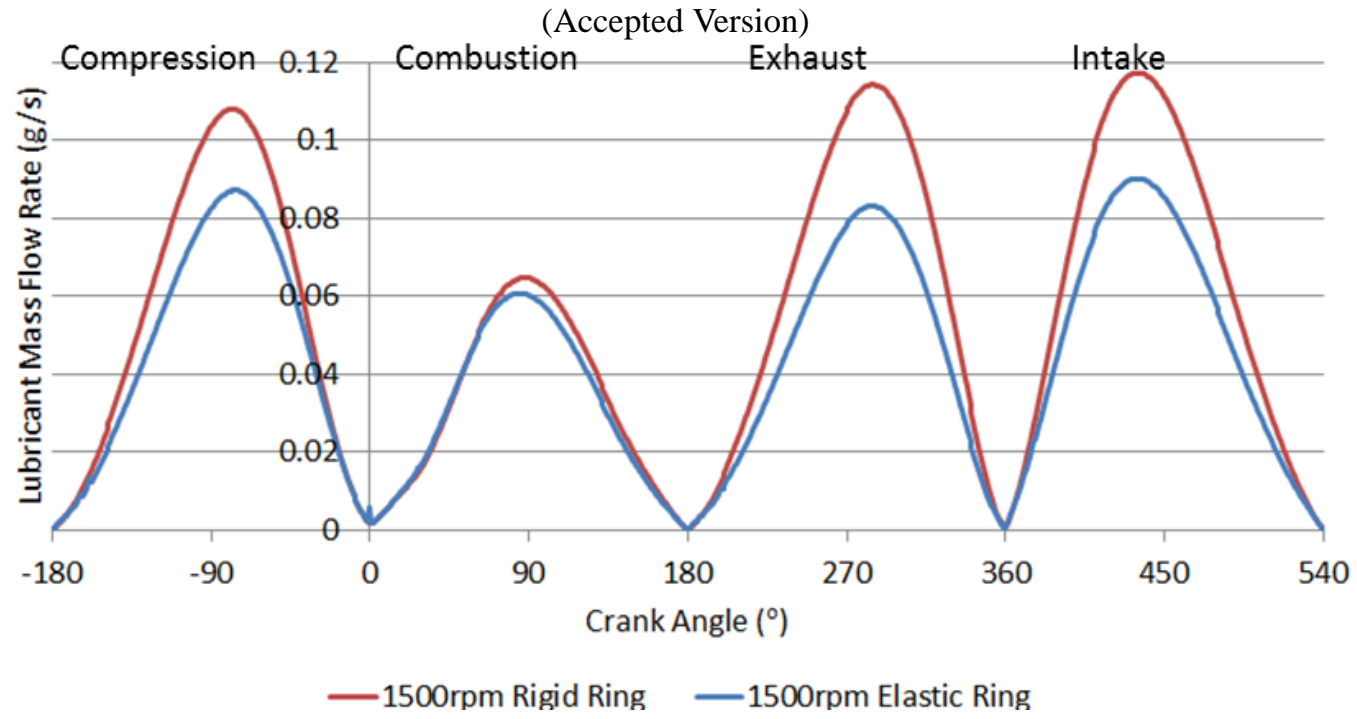

Figure 8: Lubricant mass flow rate comparison of rigid and elastic ring analysis at ring's middle cross section for lubricant temperature $40^{\circ} \mathrm{C}$

As it would be expected, the minimum film thickness occurs at the TDC in the transition between the compression and power strokes. This is because of the momentary cessation of lubricant entrainment due to the lack of relative motion of contiguous surfaces. Such localised minima also occur at all the dead centre reversals in all engine strokes. In the power stroke, the thin lubricant film persists to the point of maximum combustion pressure, because of the combustion loading behind the ring, striving to adhere it to the bore surface. In between the piston reversals (at the TDC and BDC) the film thickness rises to a maximum at the piston mid-span and decreases thereafter in direct proportion to piston speed. Therefore, the film thickness variation between reversal points is quasi-harmonic, in line with the piston speed, given by equation (3). The least film thickness predicted is around $0.89 \mu \mathrm{m}$ at the TDC. The root mean square roughness of the counterfaces, $\sigma_{\mathrm{c}} \approx 0.48 \mu \mathrm{m}$; thus, $\lambda_{\mathrm{s}} \approx 1.85$, which indicates that at the TDC reversal and up to the point of ignition a mixed regime of lubrication would be expected. This is further verified by plotting the film shape 
Journal of Engineering for Gas Turbines and Power, Transactions of the ASME, March 2015, Vol. 137, No. 3, Paper No: GTP-14-1296; DOI: 10.1115/1.4028496

\section{(Accepted Version)}

along the ring face-width and its circumference in contact with the bore (region $A$ in figure 6). This is shown in figure 9.

The plots in figure 9 show ring profile results axially opposite the ring gap (figures 9(b) and (d)) and circumferentially (figures 9(a) and (c)) for two positions of the engine cycle (at TDC $(a, b)$ and $90^{\circ}$ past TDC (c, d)). Figure $9(a)$ shows that the ring conforms well to the cylindrical bore surface at this location (very little variation exists in the ring-bore circumferential clearance; note the scale of the plot). However, the inclusion of in-plane ring dynamics alters the minimum film thickness, even if the variation circumferentially is small. This explains the minimum film thickness difference seen in figure 6 . The low degree of minimum film thickness variation also indicates good ring sealing (its main function). However, it should be reiterated a right circular cylinder is assumed in this analysis. The film thickness varies more along the ring face-width, shown in figure $9(\mathrm{~b})$ with contact pressures confined to the load bearing central ring land. The narrowly spread pressure distribution is formed along the central load bearing region of the ring. At the instant considered (transition between the compression to power stroke), the conjunctional inlet is at the top face of the ring with a chamber pressure of $2.3 \mathrm{MPa}$ (23 bar at the ordinate intersection of pressure curve in figure 2). The pressure at the outlet of the ring is considered to be atmospheric in this analysis. This pressure gradient, rising further to the point of maximum pressure at the crank angle of $20^{\circ}$ (figure 2) creates pressure-induced friction, which together with asperity friction account for the sharp rise rate in frictional power loss in figure 7. 
Journal of Engineering for Gas Turbines and Power, Transactions of the ASME, March 2015, Vol. 137, No. 3, Paper No: GTP-14-1296; DOI: 10.1115/1.4028496
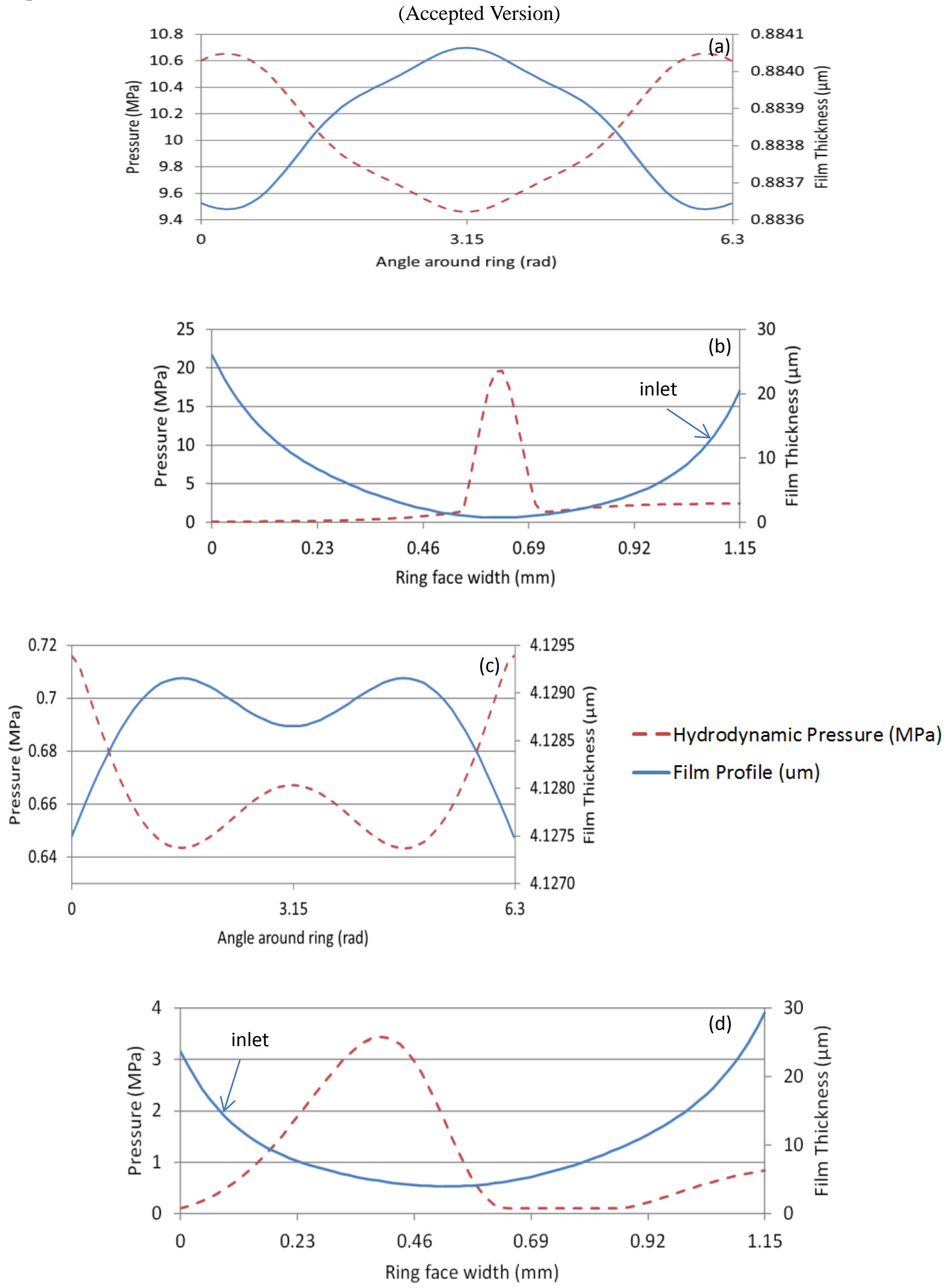

Figure 9: Circumferential and axial profiles of the lubricant pressure and film shape at TDC

$(a, b)$ and $90^{\circ}$ past TDC (c, d) 
Journal of Engineering for Gas Turbines and Power, Transactions of the ASME, March 2015, Vol. 137, No. 3, Paper No: GTP-14-1296; DOI: 10.1115/1.4028496

\section{(Accepted Version)}

The corresponding results for the piston in position B (figure 6) are shown in figures 9(c) and (d). Comparing the latter to figures $9(\mathrm{a})$ and (c) it can be seen that whilst the same overall conformity to the liner is maintained, the film shape is altered (affected by the ring modal response, as demonstrated by Baker et al [35]). The thickness of the film is significantly larger, in line with the increased lubricant entrainment $\left(\lambda_{s} \approx 8.6\right.$ indicates fully developed hydrodynamic lubrication). Figure 8 shows the increase in lubricant flow through the ringliner contact with a corresponding increase in frictional power loss predicted in figure 7 . The inlet at the piston mid-span in the power stroke (area B in figure 6) is on the crank side (figure $9(d)$ ), with the outlet pressure at the top face of the ring being the gas pressure of 1 MPa (10 Bar, see figure 2 for the crank-angle of $90^{\circ}$ ). The film pressure rises to this value (figure $9(d))$. The film thickness is predicted at $30 \mu \mathrm{m}$ in this case. However, in practice because of high temperatures in the combustion chamber, such a film of lubricant is unlikely to occur and the prediction is as the result of rather idealised isothermal exit boundary conditions that are commonly used as is the case so far in the current analysis. It should also be noted that the profiles in figures $9(b)$ and (d) appear to have been reversed due to the change in the direction of entraining motion at reversal.

Figures 10-12 show results for the same conditions as in figures $6-8$, but for engine speeds of $1000 \mathrm{rpm}$ and $2000 \mathrm{rpm}$, respectively. The same trend is seen, with the elastic ring analysis, predicting lower film thickness values than when a rigid ring is assumed. This translates to higher power loss predictions, as shown in figure 11. 
Journal of Engineering for Gas Turbines and Power, Transactions of the ASME, March 2015, Vol. 137, No. 3, Paper No: GTP-14-1296; DOI: 10.1115/1.4028496

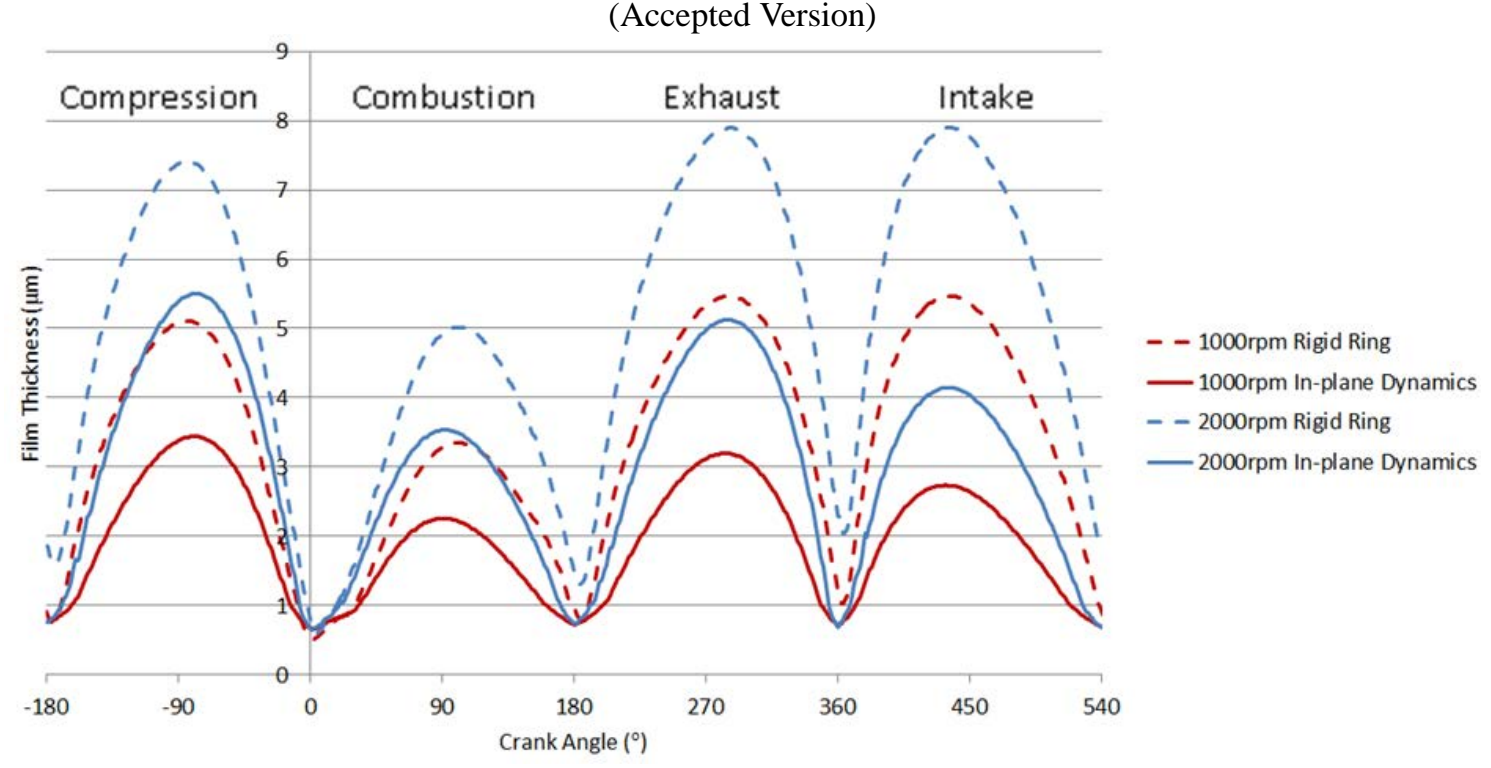

Figure 10: Engine speed effect on minimum film thickness predictions for rigid and elastic rin g analysis (lubricant temperature $40^{\circ} \mathrm{C}$ )

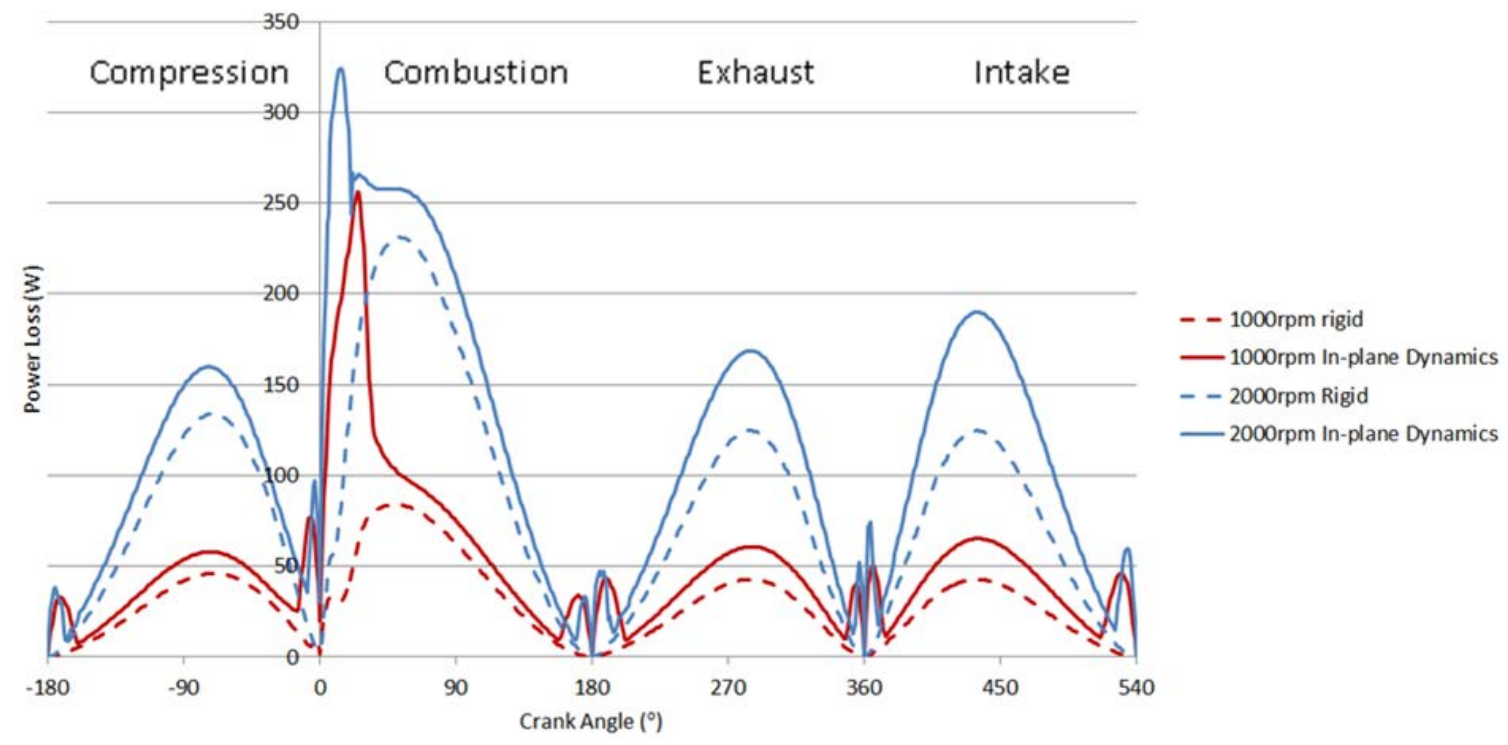

Figure 11: Effect of engine speed on frictional power loss predictions for rigid and elastic ring analysis (lubricant temperature $40^{\circ} \mathrm{C}$ ) 
Journal of Engineering for Gas Turbines and Power, Transactions of the ASME, March 2015, Vol. 137, No. 3, Paper No: GTP-14-1296; DOI: 10.1115/1.4028496

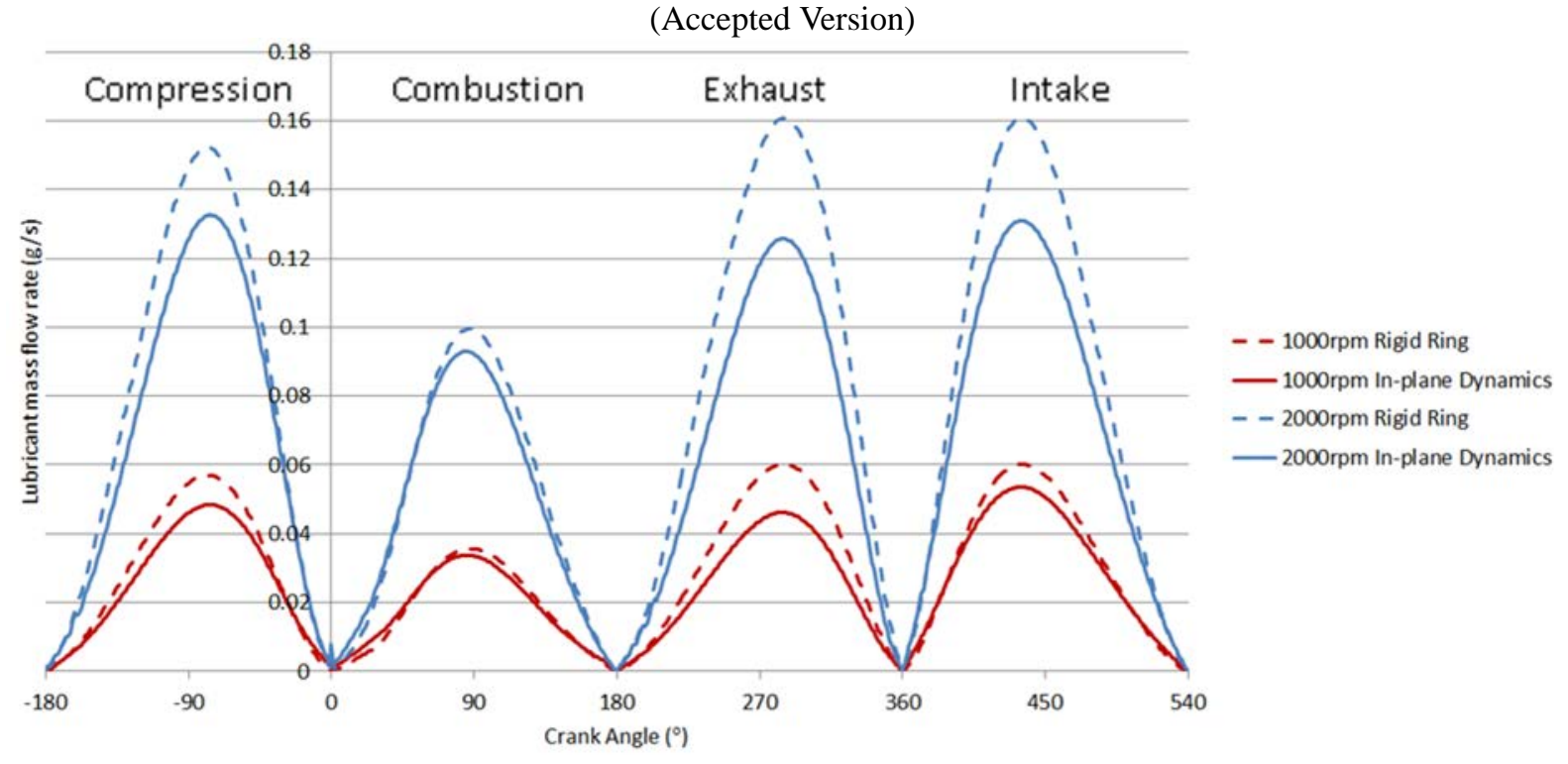

Figure 12: Effect of engine speed on lubricant flow rate predictions for rigid and elastic ring analysis (lubricant temperature $40^{\circ} \mathrm{C}$ )

Temperature plays a crucial role in the ring behaviour. Firstly, it reduces the lubricant viscosity, thus its load carrying capacity (see equations $(6,7)$ ). This yields thinner lubricant films. The reduced film thickness and lubricant viscosity can lead to mixed regime of lubrication in parts of the engine cycle. Furthermore, viscous friction is affected by the ratio of $\eta / h$ as well as increased pressure gradient with a thinning conjunction (equations (33, 34)). Therefore, for a realistic analysis (particularly NEDC hot steady state cycle at low engine speed in crawling traffic), estimation of lubricant temperature is an essential pre-requisite. On a recent study, Morris et al [50], using analytical thermal balance method, have shown that the average instantaneous lubricant temperature in the ring-liner conjunction is mainly due to liner temperature as the result of combustion thermal flux. This means that the effective lubricant temperature, $\theta$ (equation (5)) may be considered to be that of the liner at any instant of time, with a very small transient rise due to its passage through the contact. 
Journal of Engineering for Gas Turbines and Power, Transactions of the ASME, March 2015, Vol. 137, No. 3, Paper No: GTP-14-1296; DOI: 10.1115/1.4028496

Therefore, for simplicity, the current analysis uses the bulk inlet oil temperature for steady state NEDC cycle analysis. This means $\theta=40^{\circ} \mathrm{C}$ for steady state "cold" NEDC cycle, $\theta=120^{\circ} \mathrm{C}$ for the "hot" steady state cycle and $80^{\circ} \mathrm{C}$ in transience between these cases. The temperature throughout the engine cycle remains constant for each of the considered cases.

Figures 13-15 show predictions at various parts of a typical NEDC cycle (cold and hot steady states and the temperature rise in transience). As expected the film thickness is reduced due to reduced load carrying capacity at a higher temperature (figure 13). Correspondingly, a greater contribution is noted by asperity friction at the TDC reversal, extending to the point of maximum pressure in power stroke (figure 14). The viscous friction is reduced throughout the whole engine cycle because of the reduced lubricant viscosity at higher temperatures. However, this marginal reduction in frictional power loss is more than offset by the significant increase due to boundary interactions (figure 14). Figure 15 shows the predicted lubricant flow rate for the studied engine conditions. Clearly, a fully flooded condition is assumed. In practice, this is unlikely to be the case, particularly in the compression and exhaust strokes, where an insufficient volume of free surface-adhered film on the liner surface would be expected to feed the contact inlet. 
Journal of Engineering for Gas Turbines and Power, Transactions of the ASME, March 2015, Vol. 137, No. 3, Paper No: GTP-14-1296; DOI: 10.1115/1.4028496

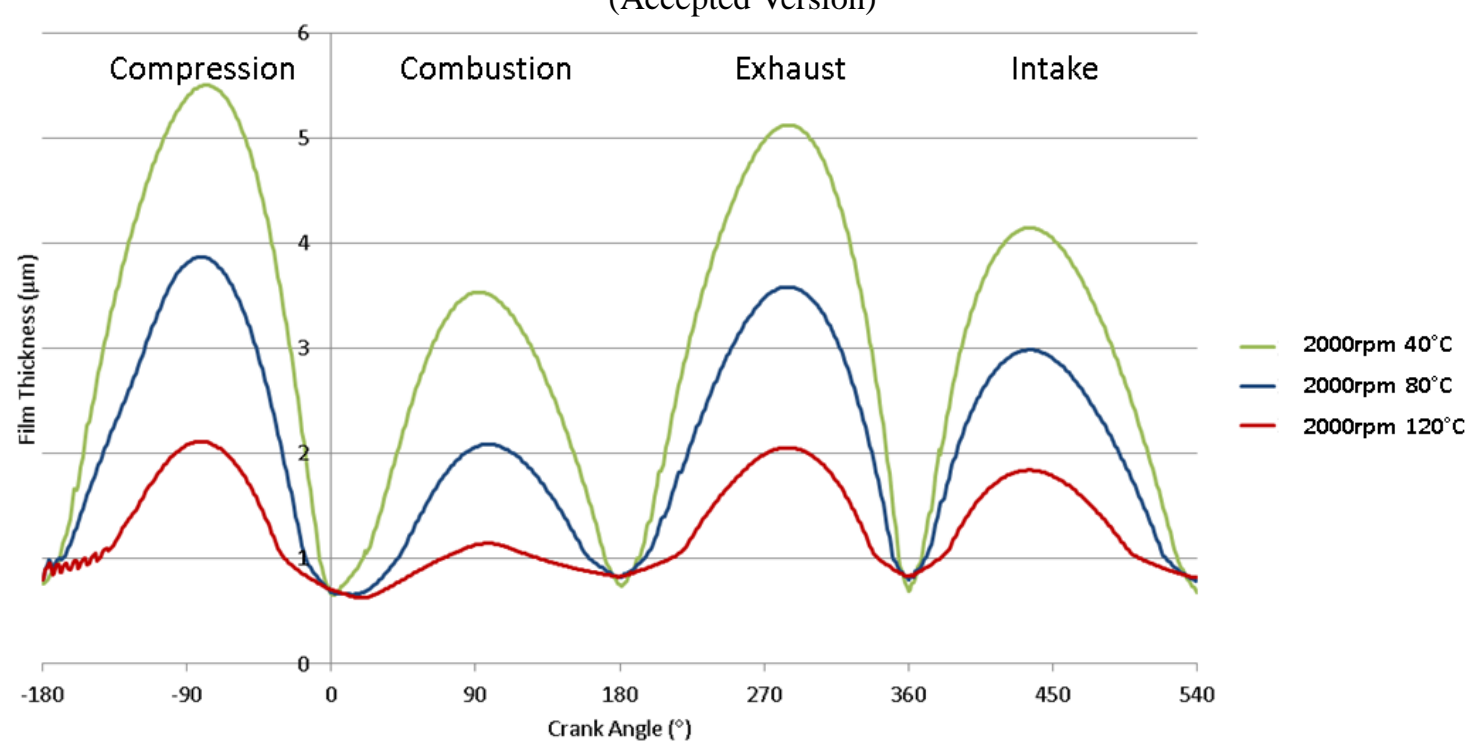

Figure 13: Effect of temperature on the minimum film thickness (elastic ring analysis)

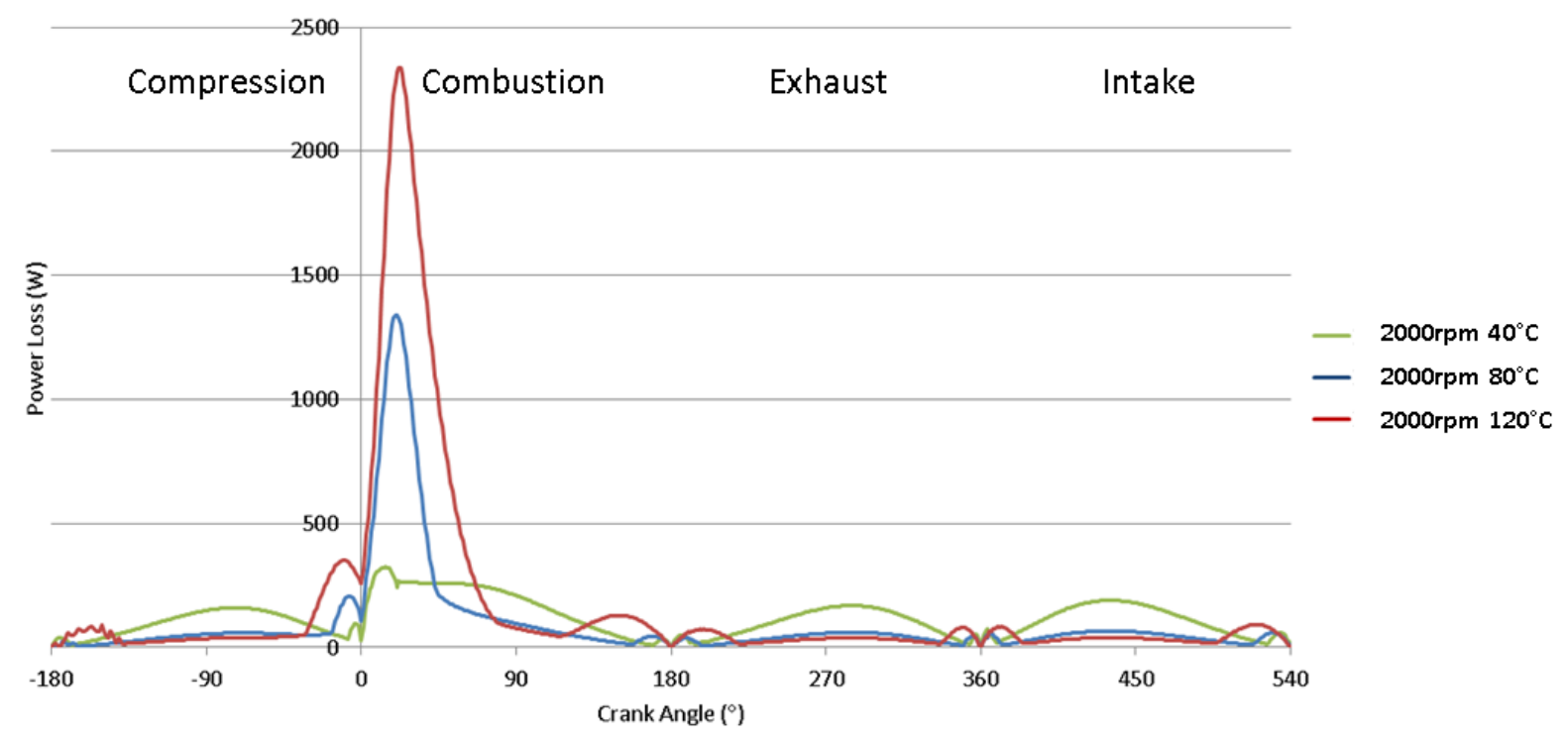

Figure 14: Effect of temperature on friction power loss (elastic ring analysis) 
Journal of Engineering for Gas Turbines and Power, Transactions of the ASME, March 2015, Vol. 137, No. 3, Paper No: GTP-14-1296; DOI: 10.1115/1.4028496

(Accepted Version)

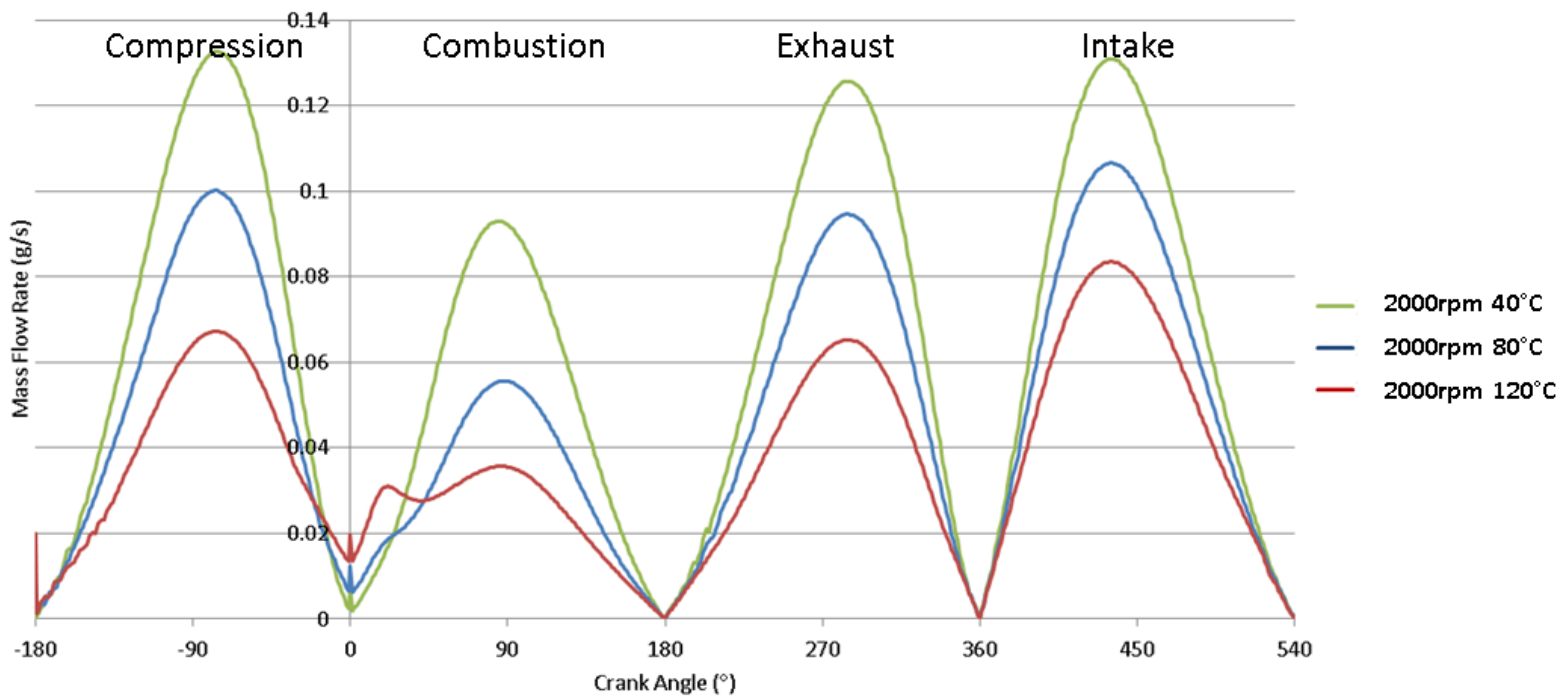

Figure 15: Effect of temperature on lubricant mass flow rate (elastic ring analysis)

Figure 16 is the result of a series of simulated conditions at different nominal engine speeds (idling and low speed crawling), typical for the vehicle under investigation. They correspond to the aforementioned steady state and transient parts of the NEDC cycle. The energy consumed is calculated over a complete engine cycle for different engine speeds and temperatures. It is interesting to note that the percentage energy consumed through parasitic frictional losses in fact follows the presumed worst case scenarios of the "cold" and "hot" steady state parts of the NEDC, something that has been ascertained through fuel consumption and emission tests, but not hitherto confirmed through rigorous analysis. However, the picture is more complex in the case of an elastic ring, subject to modal behaviour. For a rigid ring, the predictions show the variation of the percentage energy consumed to be rather independent of the prevailing conditions, which does not conform to actual vehicle tests. On the other hand, results obtained for an elastic ring are in line with test results and rationale observations. The percentage losses also agree with the reported range of $0.06-1.5 \%$ by Richardson [21] for those attributed to the top compression ring-liner 
Journal of Engineering for Gas Turbines and Power, Transactions of the ASME, March 2015, Vol. 137, No. 3, Paper No: GTP-14-1296; DOI: 10.1115/1.4028496

(Accepted Version)

conjunction. The percentage energy lost is described by:

$$
\% \text { Energy lost }=\frac{\text { Average friction power loss } * \text { Engine speed }}{\text { Fuel mass flow per cylinder } * Q_{l \mathrm{hv}}} \times 100
$$

where $Q_{\text {lhv }}$ is the lower heating value of the fuel.

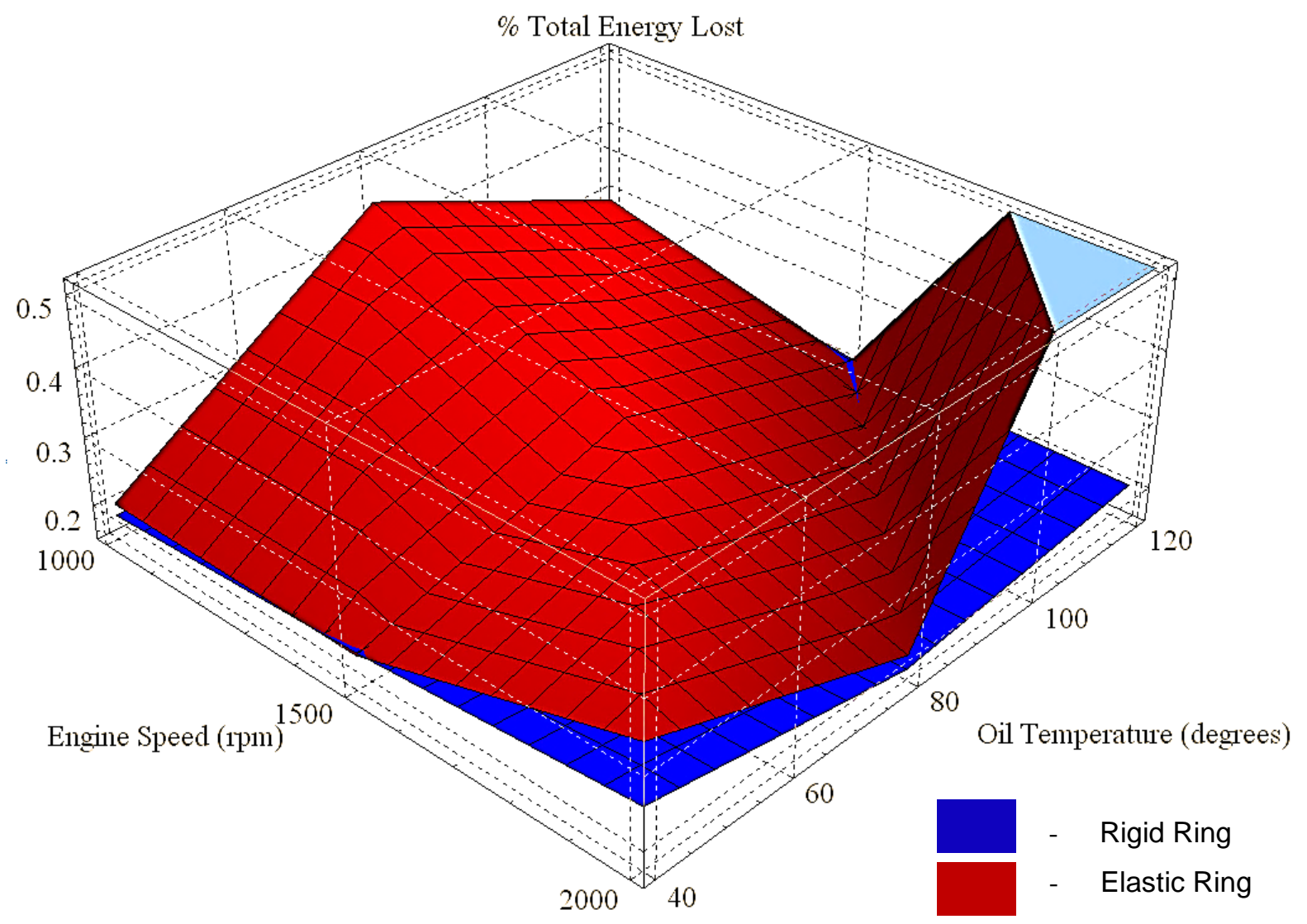

Figure 16: Total cyclic energy consumed for rigid and elastic rings

A greater change in energy loss is seen when the elastic ring analysis is implemented. However, there is no direct trend between engine temperature or speed and the energy loss. This is due to the fact that higher temperatures lower viscous friction, but also promote formation of thinner films, which in turn increases the likelihood of asperity interactions. Therefore, the relationship between the temperature-engine speed combination and total power loss is not a linear one. 
Journal of Engineering for Gas Turbines and Power, Transactions of the ASME, March 2015, Vol. 137, No. 3, Paper No: GTP-14-1296; DOI: 10.1115/1.4028496

\section{(Accepted Version)}

The validity of the numerical approach presented should be ascertained through comparison with published experimental data. Takiguchi et al [36] have provided film thickness predictions and measurements, as well as the required input data to replicate their reported study. The cylinder temperature was measured for a variety of speeds and loads, varying around $120^{\circ} \mathrm{C}$. These data are used to carry out simulation studies using the methodology presented in our work. Figures 17 and 18 show comparisons between the experimental results, presented in Takiguchi et al [36], and the analysis predictions made here. The latter have been obtained at engine speeds (2000rpm and 2400rpm), showing reasonable agreement with measurements. The agreement is better for the case of an assumed elastic ring. There are of course some differences between the predictions and measurements. There are a host of underlying reasons for this, including bore out-of-roundness (not taken into account in the analysis), and a lack of detail regarding surface topography in [36], which has meant that predictive analysis could only be carried out for an assumed smooth conjunction and a parabolic axial ring profile. The bore is assumed to be a right circular cylinder for all analyses reported here. However, experimentally measured data clearly include the various effects which induce bore out-of-roundness. Combustion chamber pressure was provided by Takiguchi et al [31]. The analysis also assumes a fully flooded inlet. Piston secondary motion is also not included in the current model, although the actual tilt of the piston has been found to be of the order of few tenths of a degree in most cases [52]. Most significantly, the analysis presumes that $100 \%$ of gas pressure acts behind the ring inner rim, loading it against the liner surface. This is an idealised condition, therefore, the difference between predicted and measured film is most pronounced in the power stroke. Nevertheless, good agreement is noted, as well as better predictions with an elastic ring 
Journal of Engineering for Gas Turbines and Power, Transactions of the ASME, March 2015, Vol. 137, No. 3, Paper No: GTP-14-1296; DOI: 10.1115/1.4028496

analysis.

(Accepted Version)

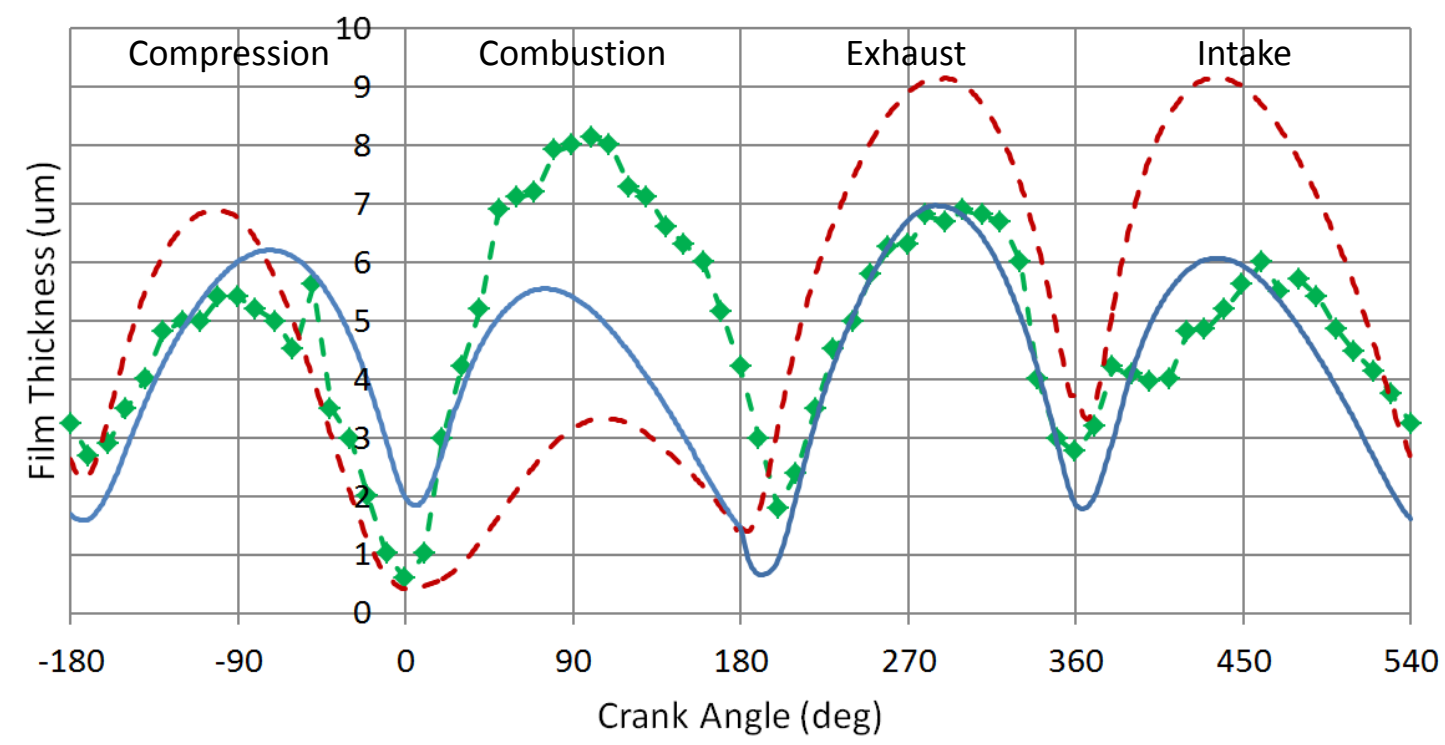

$\_-$Takiguchi Experimental 2000rpm _ - - Rigid Ring 2000rpm — Elastic Ring 2000rpm

Figure 17: Experimental data in comparison with the presented methodology (2000rpm).

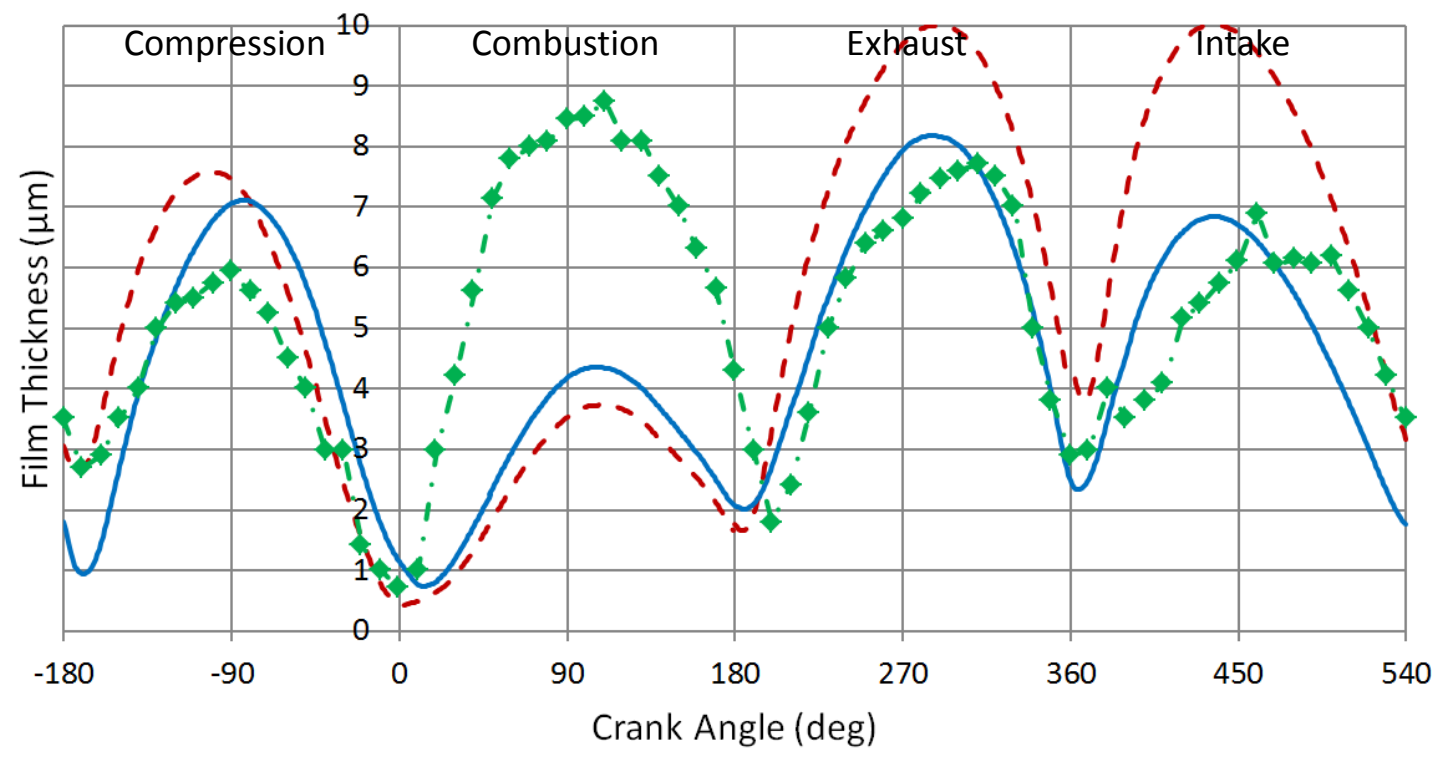

_ - - Rigid Ring 2400rpm —— Elastic Ring 2400rpm — - Takiguchi Experimental 2400rpm

Figure 18: Experimental data in comparison with the presented methodology (2400rpm).

\section{Conclusions}


Journal of Engineering for Gas Turbines and Power, Transactions of the ASME, March 2015, Vol. 137, No. 3, Paper No: GTP-14-1296; DOI: 10.1115/1.4028496

\section{(Accepted Version)}

Tribological analyses of ring-bore contact generally omit the ring transient modal behaviour.

However, it is intuitive that the compression ring would be subject to elastodynamic response during the combustion cycle, as the combination of high velocities and pressures act on its relatively thin structure. Therefore, assuming rigid ring behaviour can lead to unrealistic assessment of its sealing function, as well as estimation of ring-bore friction. The current study shows that transient in-plane ring dynamics significantly affects the ring-bore gap and thus the generated friction as well lubricant mass flow rate through the conjunction. These findings also conform favourably with the experimental work of Takiguchi et al [36]. The predictions show reduced lubricant film thickness as the result of ring dynamics, ensuring better ring sealing at the expense of increased energy consumed due to friction. An important observation is that the ring transient response is sufficiently fast to affect ringbore friction at the sliding speeds investigated in the current analysis. A rigid ring analysis implies otherwise. Temperature rise promotes thinner films, higher friction and lower mass flow rate. It also leads to mixed/boundary lubrication conditions.

Tribo-dynamics of ring-bore conjunction is a multi-variate problem. Therefore, all analyses embody certain assumptions in order to make the problem numerically tractable within sensible simulation times. The current analysis is no exception. In particular, future extensions of this work should aim to remove some of the assumptions made in the current study, such as $100 \%$ gas pressure loading of compression ring (a commonly made assumption). This requires the addition of a gas flow model within the piston ring-pack. By adding such a feature, ring-bore conformability would alter, thus the ring sealing and hence cavitation. Therefore, a more pertinent lubricant inlet availability model (rather than the fully flooded condition) and outlet cavitation algorithms may also be appended. 
Journal of Engineering for Gas Turbines and Power, Transactions of the ASME, March 2015, Vol. 137, No. 3, Paper No: GTP-14-1296; DOI: 10.1115/1.4028496

(Accepted Version)

\section{Acknowledgements}

The authors wish to express their gratitude to the Engineering and Physical Sciences Research Council (EPSRC) for the funding of the Encyclopaedic Program Grant (www.Encyclopaedic.org), under which this research is carried out in collaboration with a consortium of industry and academic institutions. Thanks are also due to Aston Martin for financial and technical support.

\section{References}

[1] King, J., 2007 'The King Review of low carbon cars Part I: the potential for CO2 reduction', HMSO

[2] Lamb, H, 1888, "On the Flexure and Vibrations of a Curved Bar", Proc. Lond. Math. Soc., 19, pp 365-376

[3] Den Hartog, J.P, 1928 "The Lowest Natural Frequency of Circular Arcs", Phil. Mag., Vol. 5, pp. $400-408$

[4] Volterra, E. and Morell, J. D, 1961 “Lowest Natural Frequency of Elastic Arc for Vibrations outside the Plane of Initial Curvature", Trans. ASME, J. App. Mech., 28, pp. 624-627

[5] Love, A. E. H., 1944 "A Treatise on Mathematical Theory of Elasticity", Dover Publications, New York

[6] Timoshenko, S. and Goodier, J.N., 1951 Theory of Elasticity, 2nd Ed., McGraw-Hill, Inc., USA 
Journal of Engineering for Gas Turbines and Power, Transactions of the ASME, March 2015, Vol. 137, No. 3, Paper No: GTP-14-1296; DOI: 10.1115/1.4028496

(Accepted Version)

[7] Archer, R. R, 1960 "Small Vibrations of Thin Incomplete Circular Rings", Int. J. Mech. Sci.,

1, pp. $45-56$

[8] Ojalvo, I.U., 1962 “Coupled Twist-Bending Vibrations of Incomplete Elastic Rings”, Int. J. Mech. Sci., 4, pp. 53-72

[9] Lang, T. E, 1962 "Vibration of Thin Circular Rings, Part 1", Jet Propulsion Laboratory Technical Report No. 32-261

[10] Auciello, N. M., De Rosa, M. A., 1994 "Free Vibrations of Circular Arches: A Review", J. Sound and Vibration, 176, pp. 433-458

[11] Kang, K. J., Bert, C. W. and Striz, A. G., 1996 "Vibration and Buckling Analysis of Circular Arches Using DQM" Computers \& Structures, 60, pp. 49-57

[12] Namazian, M., and J. B. Heywood. "Flow in the Piston-Cylinder Ring Crevices of a SI Engine." SAE paper 820088 (1982).

[13] Dowson, D., Economou, P. N., Ruddy, B. L., Strachan, P. J., and Baker, A. J. S., "Piston ring lubrication. Part II: theoretical analysis of a single ring and a complete ring pack." Energy Conservation through fluid film lubrication technology: Frontiers in research and design (1979): 23-52.

[14] Ruddy, B. L., Dowson, D., Economou, P. N., and Baker, A. J. S., "Piston-ring lubricationpart III. The influence of ring dynamics and ring twist." Energy Conservation through fluid film lubrication technology: Frontiers in research and design (1979). 
Journal of Engineering for Gas Turbines and Power, Transactions of the ASME, March 2015, Vol. 137, No. 3, Paper No: GTP-14-1296; DOI: 10.1115/1.4028496

(Accepted Version)

[15] Tian, T., 2002, "Dynamic behaviours of piston rings and their practical impact; Part 1: ring flutter and ring collapse and their effects on gas flow and oil transport", Proc. Instn. Mech. Engrs., Part J: J. Engng. Tribology, 216, 209-227

[16] D’Agostino, V. and Senatore, A., 2010,"Fundamentals of lubrication and friction of piston ring contact", in Rahnejat, H. (ed.), Tribology and dynamics of engine and powertrain-

fundamentals, applications and future trends, Cambridge, UK: Woodhead Publishing Ltd.

[17] Tung, S.C. and McMillan, M.L., 2004, Automotive tribology overview of current advances and challenges for the future, Tribology International, 37, 517-536

[18] Taylor, C.M., 1998, Automobile engine tribology - design considerations for efficiency and durability, Wear, 221, 1-8

[19] Becker, E.P., 2004, Trends in tribological materials and engine technology, Tribology International 37, 569-575

[20] Fox, M.F., Jones, C.J., Picken, D.J., Stow, C.G., 1997, The "limits of lubrication"' concept applied to the piston ring zone lubrication of modern engines, Tribology Letters, 3, 99-106

[21] Richardson, D.E., 2000, Review of power cylinder friction for diesel engines, Journal of Engineering for Gas Turbines and Power, Transactions of the ASME, 122, 506-519

[22] Priest, M. and Taylor, C.M., 2000, Automobile engine tribology - approaching the surface, Wear, 241, 193-203

[23] Furuhama, S., 1959, A dynamic theory of piston-ring lubrication: $1^{\text {st }}$ report, calculation, Bulletin of JSME, 2(7), 423-428 
Journal of Engineering for Gas Turbines and Power, Transactions of the ASME, March 2015, Vol. 137, No. 3, Paper No: GTP-14-1296; DOI: 10.1115/1.4028496

\section{(Accepted Version)}

[24] Furuhama, S., 1960, A dynamic theory of piston-ring lubrication: 2st report, experiment, Bulletin of JSME, 3(10), 291-297

[25] Furuhama, S., 1961, A dynamic theory of piston-ring lubrication: 3rd report, measurement of oil film thickness, Bulletin of JSME, 4(16), 744-752

[26] Ma, M.-T., Sherrington, I. and Smith, E.H., 1997, Analysis of lubrication and friction for a complete piston-ring pack with an improved oil availability model, Part 1: circumferentially uniform film, Proc. IMechE, Part J: J. Engineering Tribology, 211, 1-15

[27] Mishra, P.C., Balakrishnan, S. and Rahnejat, H., 2008, Tribology of compression ring-tocylinder contact at reversal, Proc. IMechE, Part J: J. Engineering Tribology, 222, 815-826

[28] Hu, Y., Cheng, H.S., Arai, T. and Kobayashi, Y., 1994, Numerical simulation of piston ring in mixed lubrication - A nonaxisymmetrical analysis, Trans. ASME, J. Tribology, 116, 470-478

[29] Bolander, N.W., Steenwyk, B.D., Kumar, A. and Sadeghi, F., 2005, Lubrication regime transitions at the piston ring-cylinder liner interface, Proc. IMechE, Part J: J. Engineering Tribology, 219, 19-31

[30] Akalin O. and Newaz, G.M., 2001, Piston ring-cylinder bore friction modeling in mixed lubrication regime: Part I-Analytical results, Trans. ASME, J. Tribology, 123, 211-218

[31] Mishra, P.C., Rahnejat, H. and King, P.D., 2009, Tribology of the ring-bore conjunction subject to a mixed regime of lubrication, Proc. IMechE, Part C: J. Mech. Engineering Science, $223,987-998$

[32]- Furuhama, S. and Sasaki, S. 1983, New device for the measurement of piston frictional forces in small engines, SAE Technical paper 831284 
Journal of Engineering for Gas Turbines and Power, Transactions of the ASME, March 2015, Vol. 137, No. 3, Paper No: GTP-14-1296; DOI: 10.1115/1.4028496

\section{(Accepted Version)}

[33] Rahmani, R., Theodossiades, Rahnejat and Fitzsimons, B., 2012, Transient elastohydrodynamic lubrication of rough new or worn piston compression ring conjunction with an out-of-round cylinder bore, Proc IMechE Part J: J Engineering Tribology, 226 (4), 284305, DOI: $10.1177 / 1350650111431028$

[34] Baker, C., Rahnejat, H., Rahmani, R. and Theodossiades, S., 2011, Analytical evaluation of fitted piston compression ring: modal behaviour and frictional assessment, SAE Technical Paper: 2011-01-1535

[35]- Baker, C.E., Theodossiades, S., Rahnejat, H. and Fitzsimons, B. 2012, Influence of inplane dynamics of thin compression rings on friction in internal combustion engines, Trans ASME J. Eng. Gas Turb Power, 134, DOI: 10.1115/1.4006690

[36] Takiguchi, M., Sasaki, R., Takahashi, I., Ishibashi, F., Furuhama, S., Kai, R. and Sato, M., 2000, "Oil Film Thickness Measurement and Analysis of a Three Ring Pack in an Operating Diesel Engine", SAE Technical Paper 2000-01-1787

[37]- Rahnejat, H., 1998 Multi-body Dynamics: Vehicles, Machines and Mechanisms, Joint Publishers: SAE (Warrendale, Pa, USA) and PEP (IMechE, UK), ISBN 0768002699

[38] Han, Dong-Chul, and Jae-Seon Lee. "Analysis of the piston ring lubrication with a new boundary condition." Tribology international 31.12 (1998): 753-760

[39] Yang, P., Cui, J., Jin, Z.M. and Dowson, D., 2005, Transient elastohydrodynamic analysis of elliptical contacts. Part 2: thermal and Newtonian lubricant solution', Proc. IMechE, Part J: J. Engineering Tribology, 219, 187-200

[40]- Houpert, L., 1985, “New results of traction force calculations in elastohydrodynamic contacts", Trans ASME, J. Tribology, 107, 241-248 
Journal of Engineering for Gas Turbines and Power, Transactions of the ASME, March 2015, Vol. 137, No. 3, Paper No: GTP-14-1296; DOI: 10.1115/1.4028496

[41] Gohar, R. and Rahnejat, H., 2008, Fundamentals of Tribology, Imperial College Press, London, UK, ISBN 10-1-84816-184-0

[42]- Bin Chik, A. and Fessler, H. (1966) 'Radial pressure exerted by piston rings', J. Strain Analysis , I ( 2), pp. 165-171

[43]- Greenwood, J.A. and Tripp, J.H., 1970, The contact of two nominally flat rough surfaces, Proc. IMechE, 185, 625-634

[44]- Teodorescu, M., Taraza, D., Henein, N.A. and Bryzik, W., 2003 'Simplified elastohydrodynamic friction model of the cam-tappet contact', SAE Pap. No. 2003-01-0985, 2003 [45] Tian, T., Noordzij, L.B., Wong, V.W. and Heywood, J.B., 1998, “Modeling piston-ring dynamics, blowby, and ring-twist effects", Trans. ASME, J. Eng Gas Turb Power, 120, 843-854 [46] Johnson, K.L. and Greenwood, J.A. 1980, 'Thermal analysis of an Eyring fluid in elastohydrodynamic traction' Wear, 61, pp. 353-374.

[47] Teodorescu, M., Kushwaha, M., Rahnejat, H. and Rothberg, S.J., 2007, “Multi-physics analysis of valve train systems: from system level to microscale interactions", Proc. IMechE, Part K: J. Multi-body Dyn., 221, pp. 349-361

[48] Hoffmann, K.A. and Chiang, S.T., 1993, Computational fluid dynamics for engineers Volume I, A Publication of Engineering Education System, Wichita, Kansas, USA

[49] "WHO adds pressure for stricter Euro-5 standards", Bull., News from the European Federation for Transport and Environment, 146, March 2006 
Journal of Engineering for Gas Turbines and Power, Transactions of the ASME, March 2015, Vol. 137, No. 3, Paper No: GTP-14-1296; DOI: 10.1115/1.4028496

(Accepted Version)

[50] Morris, N., Rahmani, R., Rahnejat, H., King, P.D. and Fitzsimons, B., 2013, “Tribology of piston compression ring conjunction under transient thermal mixed regime of lubrication", Tribology Int., 59, 248-258

[51] Richardson, D., 2000 "Review of Power Cylinder Friction for Diesel Engines", Trans. ASME, J. Eng. Gas Turb Power, 122 (4), pp.506-519

[52] Balakrishnan, S. and Rahnejat, H. 2005 "Isothermal transient analysis of piston skirt-tocylinder wall contacts under combined axial, lateral and tilting motion", J. Phys, D: Appl. Phys., 38(5), 787 doi:10.1088/0022-3727/38/5/018 